The University of Maine

DigitalCommons@UMaine

Electronic Theses and Dissertations

Fogler Library

$12-2001$

\title{
Validation of a Sun-Exposure Questionnaire for Adolescent Girls
}

Jennifer L. Cobb

Follow this and additional works at: http://digitalcommons.library.umaine.edu/etd

Part of the Food Science Commons, and the Nutrition Commons

\section{Recommended Citation}

Cobb, Jennifer L., "Validation of a Sun-Exposure Questionnaire for Adolescent Girls" (2001). Electronic Theses and Dissertations. 94. http://digitalcommons.library.umaine.edu/etd/94

This Open-Access Thesis is brought to you for free and open access by DigitalCommons@UMaine. It has been accepted for inclusion in Electronic Theses and Dissertations by an authorized administrator of DigitalCommons@UMaine. 


\title{
VALIDATION OF A SUN-EXPOSURE QUESTIONNAIRE FOR ADOLESCENT GIRLS
}

By

Jennifer L. Cobb

B.A. University of Maine, 1991

B.S. University of Maine, 1999

\author{
A THESIS \\ Submitted in Partial Fulfillment of the \\ Requirements for the Degree of \\ Master of Science \\ (in Food Science and Human Nutrition)
}

The Graduate School

The University of Maine

December, 2001

Advisory Committee:

Susan S. Sullivan, Assistant Professor of Human Nutrition, Advisor

Adrienne A. White, Associate Professor of Human Nutrition

William Halteman, Associate Professor of Mathematics 


\title{
VALIDATION OF A SUN-EXPOSURE QUESTIONNAIRE \\ FOR ADOLESCENT GIRLS
}

\author{
By Jennifer L. Cobb \\ Thesis Advisor: Dr. Susan S. Sullivan \\ An Abstract of the Thesis Presented \\ in Partial Fulfillment of the Requirements for the \\ Degree of Master of Science \\ (in Food Science and Human Nutrition) \\ December, 2001
}

Sunlight is a major contributor to an individual's vitamin D status. Determinants of sun exposure have been used in conjunction with dietary data to study the effect of sunlight on bone health of elderly populations. Sun-exposure questionnaires to assess vitamin D status have not been utilized or tested in populations of children in the United States. This is the first questionnaire, used in accordance with vitamin $\mathrm{D}$ research, to be tested against an objective measure of sun exposure and to account for diurnal variation in ultraviolet B (UVB) ray strength. The objective of this study was to develop and validate a sun-exposure questionnaire for adolescent girls and to further investigate the potential for skin synthesis of previtamin $D_{3}\left(\mathrm{pre}_{3}\right)$ in northern climates. Thirty-five girls (ages 9-15) from northeastern Maine wore a polysulphone (PS) film badge for one day. The sun-exposure questionnaire was administered the following day. Minutes spent outdoors during each hour of the day were corrected for the strength of the UVB rays during that hour. The correction factor was established using UVB data generated from a USDA UVB Monitoring Site. Corrected minutes were compared with PS badge readings for each subject. A series of PS badges and ampules containing 7-dehydrocholesterol 
were exposed each hour of the day to further investigate the effect of time of day on cutaneous pre $\mathrm{D}_{3}$ synthesis. Subject self-reported minutes outdoors, corrected for the time of day, strongly correlated with the change in absorbance $(\Delta A)$ of PS badges $(r=0.71$, $\mathrm{p}=0.000$ ). In conclusion, relative to each other, adolescent girls were able to report time spent outdoors, and time of day spent outdoors is a crucial component of a sun-exposure questionnaire. Because daily UVB data is available in virtually any locale in the United States, the questionnaire and the correction factor for the time of day can be easily adapted for use in a variety of research settings. 


\section{DEDICATION}

For those who are dearest to me, my parents, Gary and Elizabeth Cobb, my grandparents, Floyd and Maudie Cobb, my brother, Andy, and Lionel. Thank you for your unconditional love and support.

“...Oh, they tell me of a home where no storm clouds rise,

Oh, they tell me of an uncloudy day..."

-Willie Nelson 


\section{ACKNOWLEDGMENTS}

I would like to acknowledge my advisor, Dr. Susan S. Sullivan. The process of devising and working through this study and its culmination in written form is as much due to her efforts as it is due to mine. I am grateful for her guidance, encouragement, advice, countless hours of proofreading, and helping me work through some mindstraining details of this work. I will always remember our mutual excitement of a revelation and the satisfaction of problem solving and will always appreciate the humor and spontaneous laughter bred out of our frustration and tired brains.

I would like to express my sincere gratitude to Dr. Adrienne White, a member of my thesis advisory committee and my internship advisor. Dr. White has been a source of advice and gentle guidance throughout my academic career. I would also like to thank my thesis committee advisor, Dr. William Halteman. I very much appreciated being able to go over the methodologies and analysis of my study with Dr. Halteman, and leaving with the reassurance that I was on the right track.

Acknowledgements would not be complete without expressing my gratitude to Dr. Richard Cook, Dr. Dorothy Klimis-Zacas, Mrs. Katherine Musgrave, Dr. Rod Bushway, Dr. Al Bushway, Dr. Mary Ellen Camire and Pat Stoddard. Not only have I gained a fantastic education, but I have also formed friendships in a supportive and positive environment. I have received nothing but words of encouragement from everyone in the department.

I am fortunate to have had the opportunity to collaborate with and receive advice from experts in the fields of vitamin $\mathrm{D}$ and atmospheric science. I have gained incredible knowledge about materials and instruments that were once completely unfamiliar to me 
because of the coaching and advice from these fine researchers. I would like to thank Dr. Clifford J. Rosen for his encouragement and advice during the initial stages of this project and for connecting me to Dr. Michael Holick. It is solely due to Dr. Rosen that I am presenting this study at the Biologic Effects of Light Symposium.

I am indebted to Dr. Michael Holick and Dr. Tai Chen at the Vitamin D, Skin and Bone Research Laboratory, Boston University School of Medicine for supplying and analyzing provitamin $\mathrm{D}$ ampules used in this study. Much of my knowledge of cutaneous vitamin D synthesis has been gained from reading Dr. Holick's work. I am particularly grateful to Dr. Tai Chen for patiently responding to my questions, offering information invaluable to this study, and for his kind way of making me feel comfortable when seeking his expert advice.

Dr. Alfio Parisi and Dr. Michael Kimlin from the Centre for Astronomy and Atmospheric Research at the University of Southern Queensland, Australia graciously supplied and analyzed the polysulphone film badges for one-half the normal cost. Dr. Parisi unfailingly answered numerous questions via E-mail over the last two years and personally calculated the calibration equation used in analysis. I am grateful for sharing their expertise in UVB dosimetry. Cheers!

This study would not have been possible without the ability to obtain UVB data from the pyranometer in Presque Isle, thanks to the USDA UVB Monitoring Network operated from the Natural Resource Ecology Laboratory at Colorado State University. Because the intricacies of solar irradiation are not cut and dry to the untrained eye, I was again very fortunate that Dr. James Slusser, the director of the UVB Monitoring Network, had the patience to personally explain and to help me navigate around the UVB 
Monitoring Program Web Site. Dr. Slusser maintained interest in this project, often contacting me to see if I needed more data and connecting me with other researchers exploring the relationship between solar UVB and vitamin D. I am also grateful to Dr. Wei Gao who took the time to perform the computations and relay to me the complete spectral data. Dr. Gao also took the time to personally and graciously answer questions.

Here in Maine, Paul Nichols at the Department of Environmental Protection (DEP) went above and beyond professional courtesy to be of assistance in this project. Again, I spent a considerable amount of time talking with Paul about UVB radiation in Maine. Although it did not work out logistically, I was amazed when Paul offered to transport a UVB pyranometer from Cape Elizabeth to Bangor to calibrate the polysulphone badges. I also appreciated the hospitality of the DEP employees stationed in Presque Isle, who allowed me to "camp out" for a day next to the pyranometer with my ampules and badges.

Elaina Hopkins spent a great deal of time tediously entering UVB data into the computer. I am indebted to Elaina for helping me set up equations used for data analysis. 


\section{TABLE OF CONTENTS}

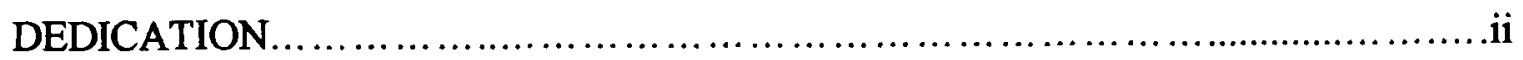

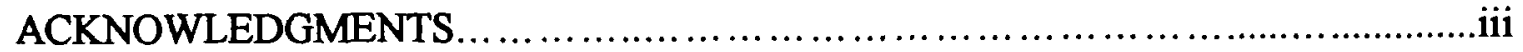

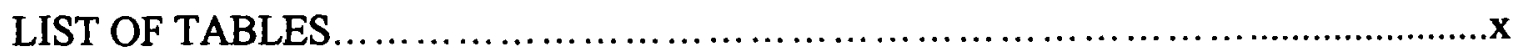

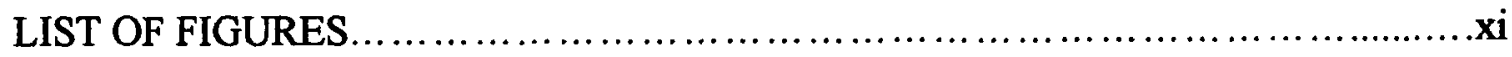

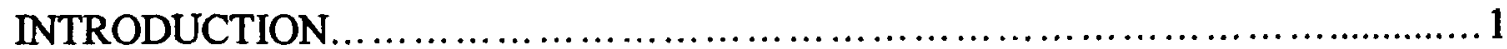

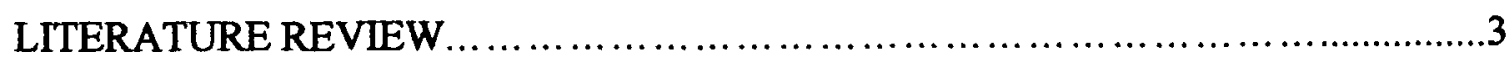

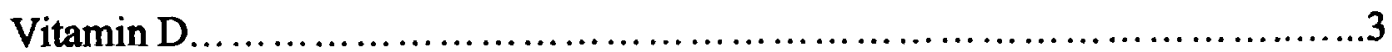

Overview of Sources and Intake Recommendations........................3

Metabolic Activation.............................................4

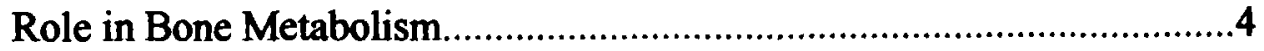

Synthesis of Vitamin D in the Skin.............................5

Impact of Sun Exposure of Serum 25(OH)D: Seasonal Variation and Possible Metabolic Effects...................................8

Sun-Exposure Questionnaire Development.............................. 12

Rationale................................................... 12

Previous Attempts............................................13

Factors to Consider in Questionnaire Design.......................15

Population............................................ 15

UVB Variation......................................... 17

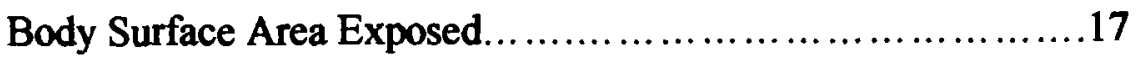

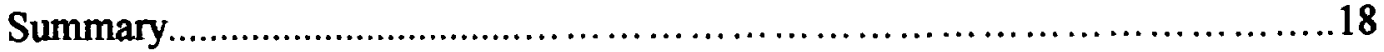

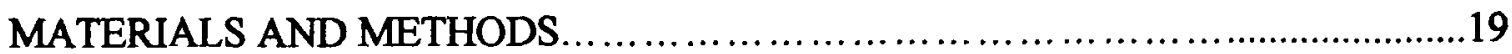

Study Design .......................................................... 19 


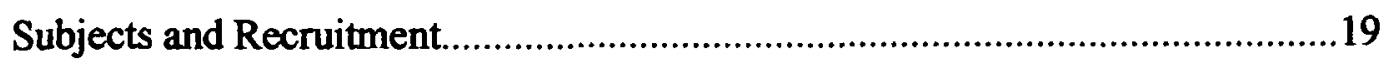

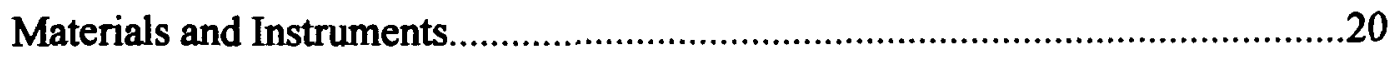

Polysulphone (PS) Film Dosimeters.......................................................20

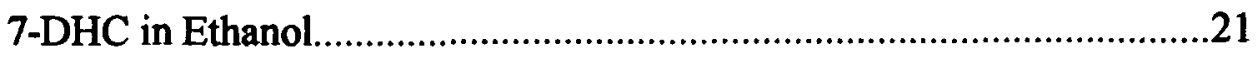

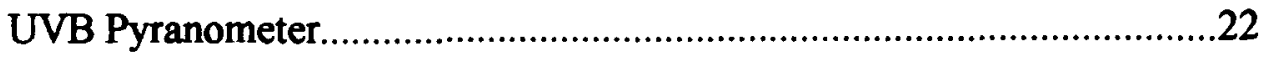

To Determine the Hourly UVB Correction Factor..........................22

To Compare Specific Wavelengths in

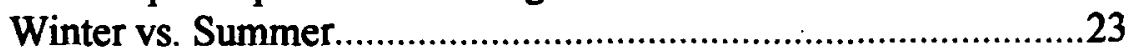

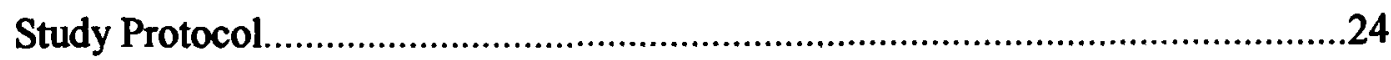

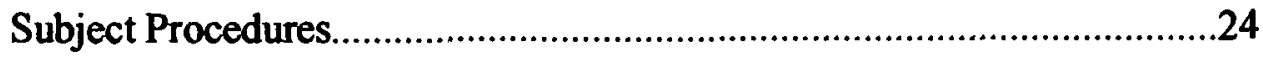

Administration and Analysis of Sun-Exposure

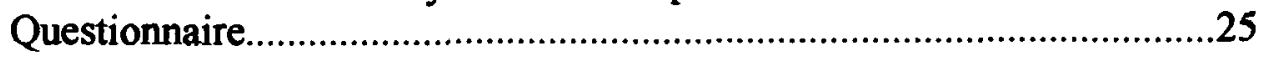

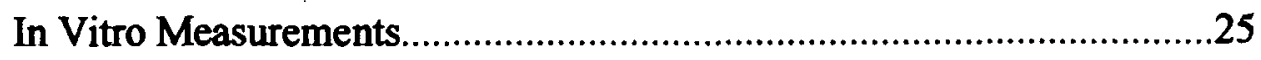

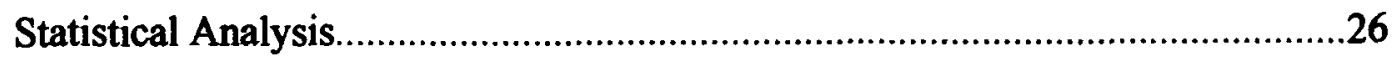

RESULTS

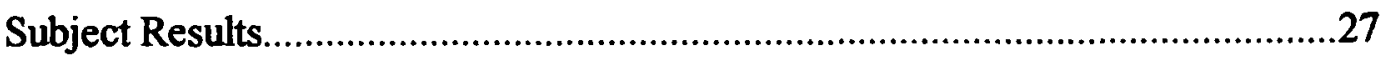

Validity of the Hourly Correction For Relative UVB Strength.............................29

Badges Exposed on Horizontal Plane....................................................29

Effect of Cloud Cover on Correction Factor.................................................30

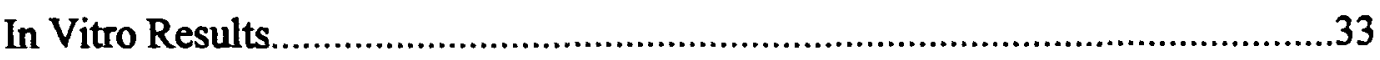

Association Between Strength of UVB Rays, Badge Results

and Previtamin $\mathrm{D}_{3}$ Synthesis.....................................................................33

Effect of Length of UVB Exposure on Formation of

Photoproducts From 7-DHC .....................................................................

Effect of Time of Day on Previtamin $D_{3}$ Synthesis...................................38 
Effect of Season on Previtamin $\mathrm{D}_{3}$ Synthesis:

August vs. February.

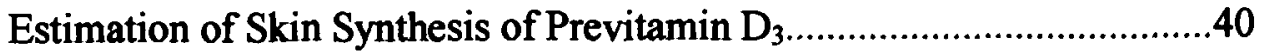

Comparison of Badge Readings in Presque Isle vs. Orono........................41

Calibration Equation.........................................................................................

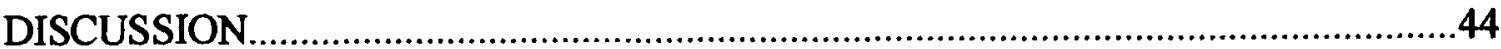

Sun-Exposure Questionnaire Validation.............................................................44

Subject Badges vs. Badges Exposed

on Horizontal Plane.

Standardizing the Correction Factor...................................................................

Factors Affecting Previtamin $\mathrm{D}_{3}$ Synthesis.......................................................

Time of Day and Length of Sun Exposure...............................................48

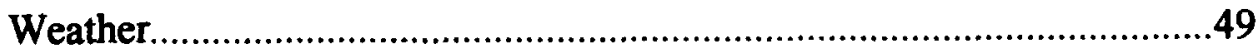

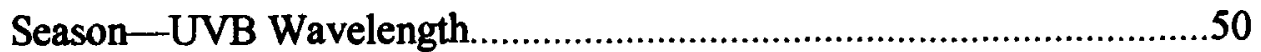

CONCLUSIONS.

APPLICATIONS AND RECOMMENDATIONS

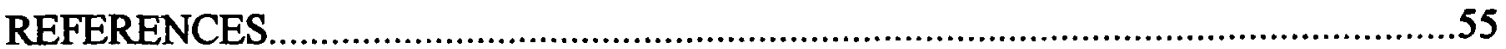

APPENDICES

A. Previtamin $\mathrm{D}_{3}$ Synthesis During a Summer and Fall Day..............................60

B. Plot of UVB Radiation on a Sunny and Cloudy August

Day in Maine.

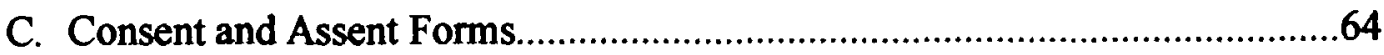

D. Badge Instruction Sheet.............................................................................67

E. Activity Sheet and Sun-Exposure Questionnaire...........................................71

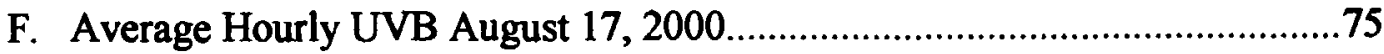


G. Example of Correcting Subject Minutes Spent Outdoors.................................77

H. Original Sun-Exposure Questionnaire........................................................79

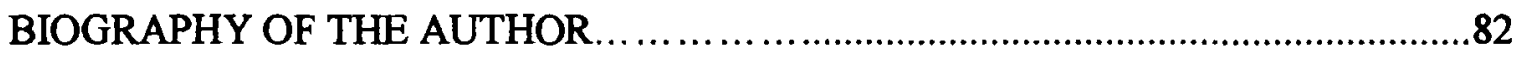




\section{LIST OF TABLES}

Table 1. Subject Self-Reported Time Outdoors and PS Badge Results

Table 2. Correlation Between Corrected Minutes Outdoors and Badge Readings by Age.

Table 3. UVB Data and Hourly Percent of Peak of Two Days in August

Table 4. Comparison of Subject Minutes Outdoors Corrected for 8/17 (Study Day) and 8/26 (Cloudless Day).

Table 5. Results of Badges and Ampules Exposed in Orono August 17, 2000

Table 6. Results of Badges and Ampules Exposed in Presque Isle August 17, 2000

Table 7. Comparison of UVB, Badge and Ampule Data in August vs. February

Table 8. Comparison of Solar Spectrum Between a Point of Time in Winter vs. Summer With Equivalent Broadband UVB

Table 9. Comparison of Badges Exposed During the Same Hours in Orono and Presque Isle

Table 10. Cumulative UVB Dose for Each Hour of the Day in Orono.

Table G.1. Example of Difference Between Total Minutes Outdoors and Total Minutes Corrected for the Hourly Strength of UVB rays of the Sun......78 


\section{LIST OF FIGURES}

Figure 1. Subject Corrected Minutes Outdoors vs. Badge Reading

Orono August 17, 2000.

Figure 2. Corrected Minutes vs. Badge Reading (Horizontal Plane)

Orono August 17, 2000.

Figure 3. Relation of Hourly Badge Readings, Previtamin $D_{3}$ Formation and UVB Levels in Orono August 17, 2000.

Figure 4. Cumulative Percent Conversion of Previtamin $D_{3}$ and Lumisterol

from 8 AM to 3 PM Presque Isle August 17, 2000 .36

Figure 5. Comparison of Percent Previtamin $\mathrm{D}_{3}$ and Lumisterol

Formation in Ampules Exposed One Hour vs. All Day

Orono August 17, 2000.

Figure 6. Hourly Production of Previtamin $\mathrm{D}_{3}$

Orono August 17, 2000

Figure 7. Plot of Orono Badge Readings vs. Presque Isle Badge Readings

Exposed During Same Times of Day.

Figure A.1. Previtamin $D_{3}$ Synthesis During a Summer and Fall

Day in Boston, MA.

Figure B.1. UVB Plot of Sunny Day in Maine................................63

Figure B.2. UVB Plot of Cloudy Day in Maine .............................63

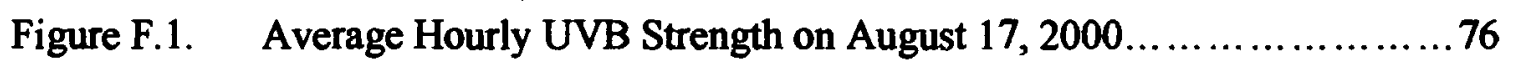




\section{INTRODUCTION}

Vitamin $\mathrm{D}$ is well known for its role in bone health and calcium homeostasis. Very few foods naturally contain vitamin $\mathrm{D}$, and a majority of the dietary intake in the United States is obtained from foods fortified with vitamin D, mainly milk (1). For most humans, it is casual exposure to sunlight that provides the daily requirement of vitamin $\mathrm{D}(2)$. The provitamin D sterol, 7-dehydrocholesterol (7-DHC), in human skin is converted to precholecalciferol (previtamin $D_{3}$ ) upon exposure to ultraviolet $B$ (UVB) radiation from the sun (3). Studies show that serum 25 -hydroxyvitamin $\mathrm{D}(25(\mathrm{OH}) \mathrm{D})$ levels, the primary indicator of vitamin D adequacy, vary greatly in relation to seasonal sunlight exposure in the elderly in the United States (4-9), and in children in countries where milk is not fortified with vitamin $D(10-16)$. These seasonal fluctuations indicate the importance of sunlight as a source of vitamin D.

The first objective of this study was to develop a sun-exposure questionnaire to assess the potential for cutaneous vitamin D synthesis. This instrument will be used in conjunction with dietary vitamin D intake to assess vitamin D status of adolescent girls in a longitudinal study of bone mineralization rates. The central issue in the design of the sunexposure questionnaire was quantifying the strength of the UVB rays during sun exposure. The strength of UVB rays varies considerably by latitude, season, and time of day. Thus cutaneous vitamin $\mathrm{D}$ production varies markedly depending on the time of day of sun exposure. The questionnaire and method of analysis were designed to account for the average hourly strength of UVB rays throughout a day. 
Because a questionnaire is not useful unless subjects can accurately report time spent outdoors, the second objective was to compare an objective measure of sun exposure to self-reported estimates of sun exposure. Results from the sun-exposure questionnaire in a sample of adolescent girls were compared with objective measurements of their UVB exposure read from polysulphone badges worn by the girls on the study day.

On the same day that the subjects wore the badges to validate the questionnaire, previtamin $\mathrm{D}_{3}$ synthesis at a particular UVB strength was determined by the use of an in vitro method that measured photoconversion of 7-DHC to previtamin $\mathrm{D}_{3}$ in ampules that were placed in the sun. Results from the 7-DHC ampule model determined the percent of previtamin $\mathrm{D}_{3}$ formed during different times of the day, further elucidating the connection between UVB strength and previtamin $D_{3}$ formation. 


\section{LITERATURE REVIEW}

\section{Vitamin D}

Overview of Sources and Intake Recommendations

Certain plants and animals contain a precursor to vitamin D. Plants contain ergosterol, which forms ergocalciferol (vitamin $\mathrm{D}_{2}$ ) upon exposure to sunlight (17). In animals, including humans, the provitamin $\mathrm{D}$ substance is 7-DHC, forming previtamin $\mathrm{D}_{3}$ in sunlight. Vitamin $\mathrm{D}$, in the form of $\mathrm{D}_{2}$ and $\mathrm{D}_{3}$, occurs naturally in very few foods that are commonly eaten. Vitamin D is found primarily in fatty fish such as salmon, herring and sardines, and fish liver oils, such as cod liver oil (18). Because there is little vitamin D in most foods, many countries fortify commonly eaten foods with vitamin D, such as milk, margarine and bread $(10,19)$. Milk is the major fortified source of vitamin $D$ in the United States (20). Many breakfast cereals are fortified with $10 \%$ of the adult Daily Value of vitamin D.

It is difficult to assess an individual's dietary intake of vitamin $D$ because vitamin $D$ levels of fortified foods can vary considerably. All milk in the United States is required to be fortified with $10 \mu \mathrm{g} /$ quart, but one study has revealed that milk often contains a great deal more or less than this amount (21).

Cutaneous synthesis of vitamin D can also vary depending on environmental factors such as latitude, season, and time of day, as well as human factors, such as clothing, sunscreen, age, skin pigment, and amount of time spent outdoors (20). Because of the lack of information concerning dietary intake and cutaneous synthesis, an Estimated Average Requirement (EAR) has not been set. The 1997 Dietary Reference Intake (DRI) suggests an Adequate Intake (AI) of $5.0 \mu \mathrm{g}(200 \mathrm{IU})$ for children and adults to the age of 50 (1). It 
is estimated that double this amount $(400 \mathrm{IU})$ can be produced in the skin during 10 minutes of summer sun on the hands and face (22).

Metabolic Activation

Vitamin $\mathrm{D}\left(\mathrm{D}_{2}\right.$ or $\left.\mathrm{D}_{3}\right)$ from the diet and from skin synthesis, transported in the blood via chylomicron remnants and vitamin D binding protein (DBP) respectively, undergoes hydroxylation of the carbon-25 in the liver to form 25 -hydroxyvitamin $\mathrm{D}(25(\mathrm{OH}) \mathrm{D})$, the major circulating form of vitamin $D(22)$. This enzyme-mediated reaction is poorly controlled, meaning hydroxylation of vitamin D occurs regardless of the amount of 25(OH)D present in the blood (18). Thus, serum 25(OH)D levels are a good indication of overall vitamin D status (23). In the kidney, a second hydroxylation at the C-1 position of the $A$ ring produces the hormone 1,25 -dihydroxyvitamin $D\left(1,25(\mathrm{OH})_{2} \mathrm{D}\right)$, the active form of vitamin $\mathrm{D}$ (22). Decreased serum calcium or increased serum parathyroid hormone (PTH) levels stimulate the hydroxylation to the active form in the kidney (22).

\section{Role in Bone Metabolism}

The active form of vitamin $\mathrm{D}, 1,25(\mathrm{OH})_{2} \mathrm{D}$ is essential in maintaining blood calcium and phosphate levels as required for the mineralization of bones and teeth. To keep a steady calcium level in the blood, vitamin D increases intestinal calcium absorption, helps release calcium from the bone, and recycles calcium in the kidney to decrease excretion (18). The primary function of $1,25(\mathrm{OH})_{2} \mathrm{D}$ in the intestine is to aid in calcium absorption by facilitating active transport. Active transport across the intestinal cell is particularly important if there is a low dietary intake of calcium (12).

One, twenty-five-dihyroxyvitamin $\mathrm{D}$ is also involved in both bone formation and resorption, depending on the serum calcium status. When serum calcium levels drop below 
normal, parathyroid hormone (PTH) is secreted from the parathyroid gland (18). Increased PTH stimulates hydroxylation of $25(\mathrm{OH}) \mathrm{D}$ to form $1,25(\mathrm{OH})_{2} \mathrm{D}$. Both PTH and $1,25(\mathrm{OH})_{2} \mathrm{D}$ are involved in complex processes that mobilize calcium and phosphate from bone to maintain plasma levels (22). A third role of vitamin $\mathrm{D}$ in maintaining serum calcium levels is through conservation of calcium in the kidney (24). Synthesis of Vitamin D in the Skin

The sterol 7-DHC is synthesized by the sebaceous glands in the first two layers of the skin, the epidermis and dermis (3). UVB radiation opens the B ring of 7-DHC, causing bond cleavage between carbons 9 and 10 to form the split sterol previtamin $D_{3}$. Previtamin $\mathrm{D}_{3}\left(\operatorname{Pre} \mathrm{D}_{3}\right)$ isomerizes in a temperature-dependent process to vitamin $\mathrm{D}$ in the skin and is transported into the circulation bound to the vitamin D binding protein (DBP) (25). Lumisterol and tachysterol are other isomers formed from previtamin $D_{3}$. These isomers do not have an affinity for DBP, do not enter the circulation and are thus considered inactive. Vitamin $D$ can be continuously synthesized from previtamin $D_{3}$ for three days after a single exposure to sunlight (3).

A toxic amount of vitamin D cannot be produced in the skin for two reasons. The concentration of previtamin $D_{3}$ reaches a maximum at about fifteen percent of the original 7-DHC content, with increased formation of inactive isomers with further exposure (26). Additionally, vitamin $\mathrm{D}$ in the skin degrades to inactive photoproducts with prolonged sun exposure (27).

The efficiency of vitamin D photoproduction is determined by characteristics of the skin. Skin contains melanin, a black pigment that accounts for color differences in the skin of different races. Tanned skin results from increased melanin production. Because 
melanin is a natural sunscreen, it competes with 7-DHC in absorbing UVB photons (20). Skin with greater amounts of melanin requires a longer sun exposure time than less pigmented skin to produce an equivalent amount of previtamin $D_{3}(26)$. Age is another factor influencing skin vitamin D synthesis. As skin ages, the capacity to produce previtamin $D_{3}$ is reduced because of the decreased amount of 7-DHC in the skin (28). Latitude and season have dramatic effects on skin synthesis of vitamin D. In northern latitudes, vitamin $\mathrm{D}$ production in the skin has been found to be greatest midsummer and decreased or nonexistent in the winter months (29). This phenomenon is due to the changing angle of the earth with respect to the sun. The solar zenith angle (SZA) describes the difference in degrees of the actual position of the sun compared to when the sun is directly overhead. During the winter, the zenith angle of the sun is increased, meaning the sun is lower in the sky, and the sun's rays must travel farther through the stratosphere. Increased absorption of photons by ozone occurs, thus decreasing the UVB radiation reaching the earth's surface (30). Also, the sun rises lower in the sky at increasing distances north or south of the equator (30). At latitudes greater than $23.5^{\circ} \mathrm{N}$ or $\mathrm{S}$, the sun never reaches a SZA of zero degrees (30). Correspondingly, the number of months per year when vitamin $\mathrm{D}$ can be synthesized declines with increasing distance from the equator $(29,31,32)$. Webb et al. (31) analyzed previtamin $D_{3}$ synthesis in skin samples and in vitro using a provitamin $D_{3}$ solution in ampules and found that previtamin $D_{3}$ synthesis did not occur in Boston (latitude $42.2^{\circ} \mathrm{N}$ ) from November to February. In fact, previtamin $D_{3}$ formation was not detected in the skin until March $17^{\text {th }}$ (31). In Edmonton, Canada $\left(52^{\circ} \mathrm{N}\right)$, previtamin $\mathrm{D}_{3}$ synthesis did not occur from the middle of October to the 
middle of April (31). Bangor, Maine is located at a latitude of $44^{\circ} 48^{\prime} \mathrm{N}$. Vitamin D synthesis is most likely absent for at least four or five months during the year in Bangor.

UVB radiation accounts for a portion of the sun's energy that reaches the earth, specifically the wavelengths from 290 to $320 \mathrm{~nm}$ (30). The wavelengths that are capable of transforming 7-DHC in the skin to previtamin $\mathrm{D}_{3}, 290-315 \mathrm{~nm}$, are referred to as the action spectrum of vitamin $\mathrm{D}$ photosynthesis. The changing intensities of wavelengths reaching the earth also affect the amount of vitamin D synthesis in the skin. The optimum wavelengths for converting 7-DHC to previtamin $\mathrm{D}_{3}$ are between $295-300 \mathrm{~nm}$ and this conversion ceases at $315 \mathrm{~nm}$ (33). The shorter wavelengths that are most responsible for vitamin $\mathrm{D}$ synthesis are stronger in the summer months than in the winter (31). In Boston, the wavelength at $296 \mathrm{~nm}$ was not detected by a spectrophotometer until March and was undetectable again by October (31).

The time of day affects previtamin $D_{3}$ synthesis, again because of the angle of the sun. The greatest amount of synthesis occurs mid-day, when the sun's rays are the strongest. When the sun is directly overhead mid-day, there is the least amount of UV photon scattering and atmospheric absorption, thus the greatest intensity reaches the skin (34). Utilizing an in vitro ampule model, $\mathrm{Lu}$ et al. (29) found that previtamin $\mathrm{D}_{3}$ formation was greatest between 11:30 AM and 12:30 PM each month of the year in Boston, Massachusetts (29). As winter approaches, the amount of time during the day when previtamin $D_{3}$ synthesis can occur narrows $(29,31)$. In Boston, previtamin $D_{3}$ synthesis was detectable from $7 \mathrm{AM}$ to $5 \mathrm{PM}$ in the summer, whereas in the spring and fall, synthesis started to occur later in the day and ceased earlier (29) (Appendix A). 
In the fall and spring, not only are there fewer hours in the day when vitamin D synthesis can occur, but also the maximum amount of previtamin $D_{3}$ formed each hour is reduced (29). For example, in Boston, the maximal formation during one hour in June was $6.5 \%$ of original $7-\mathrm{DHC}$ versus $1.5 \%$ in October (29).

Impact of Sun Exposure on Serum 25(OH)D: Seasonal Variation and Possible Metabolic Effects

The effect of latitude and season on cutaneous vitamin D synthesis is reflected in seasonal variation of $25(\mathrm{OH}) \mathrm{D}$ levels. Many studies have shown that serum $25(\mathrm{OH}) \mathrm{D}$ levels vary greatly in relation to seasonal sunlight exposure in populations that have at least some exposure to the sun. In the United States, a number of studies evaluated the contributions of dietary vitamin D and sunlight exposure to concentrations of $25(\mathrm{OH}) \mathrm{D}$ in elderly populations, both institutionalized and free-living (4-9). All of these studies indicated that both dietary vitamin D intake and sun exposure have an impact on vitamin D status. Each of these studies showed a decrease in mean serum 25(OH)D levels in winter. Although both sources of vitamin D were found to be important in a population of elderly men and women in the Framingham Heart Study cohort, it was determined that vitamin D intake was more reflective of $25(\mathrm{OH}) \mathrm{D}$ levels in women and sun exposure was a stronger determinant in men (5).

Seasonal variation in serum $25(\mathrm{OH}) \mathrm{D}$ levels is more pronounced in individuals with low vitamin D dietary intakes. Webb et al. (8) compared free-living elderly women to those in a nursing home and found that seasonal variation occurred in serum $25(\mathrm{OH}) \mathrm{D}$ concentrations of both groups, regardless of vitamin D supplementation, although the unsupplemented population had lower $25(\mathrm{OH}) \mathrm{D}$ levels and a greater seasonal variation. 
Salamone et al. (6) found that the seasonal variation in the concentration of $25(\mathrm{OH}) \mathrm{D}$ in healthy free-living elderly women was more significant in those with lower vitamin D intakes (40-321 IU/day) compared to higher intakes (446-1147 IU/day). The same results were found in preschool children in England. Those who took vitamin D supplements had less seasonal variation in serum $25(\mathrm{OH}) \mathrm{D}$ levels $(10)$.

Tropical sun exposure also attenuates the seasonal variation. Dawson-Hughes et al. (4) reported a winter decrease in serum 25(OH)D levels and increase in PTH in healthy elderly men and women, but found the seasonal decrease was less pronounced in those that had traveled to lower latitudes $\left(\leq 35^{\circ} \mathrm{N}\right)$ for at least one day the previous month.

Seasonal variation in the serum 25(OH)D levels of American children has not been extensively studied. One cross-sectional study of 62 subjects (ages 2 to 34 years old) in Wisconsin $\left(43^{\circ} \mathrm{N}\right)$ did not reveal a significant difference in total serum $25(\mathrm{OH}) \mathrm{D}$ levels during any quarter of the year, although levels were higher in one group from July to September $(37 \pm 08.7 \mathrm{ng} / \mathrm{ml})$ than in another group from January to March $(25.2 \pm 10.2$ $\mathrm{ng} / \mathrm{ml}$ ) (35). Seasonal differences were found to be most dependant on the $25(\mathrm{OH}) \mathrm{D}_{3}$ portion of total $25(\mathrm{OH}) \mathrm{D}$, obtainable from some dietary sources and synthesis in the skin from exposure to the sun. Mean serum $25(\mathrm{OH}) \mathrm{D}_{3}$ levels varied significantly from $31.2 \pm$ $8.5 \mathrm{ng} / \mathrm{ml}$ (July-September) to $16.3 \pm 7.0 \mathrm{ng} / \mathrm{ml}$ (January-March) (35). The other portion of total $25(\mathrm{OH}) \mathrm{D}, 25(\mathrm{OH}) \mathrm{D}_{2}$, is dependant only on dietary sources of vitamin $\mathrm{D}$, which may not vary during the year. Thus, even though serum $25(\mathrm{OH}) \mathrm{D}_{3}$ varied significantly among groups in different seasons, seasonal differences in total $25(\mathrm{OH}) \mathrm{D}$ were attenuated because of the steady contribution of dietary vitamin $\mathrm{D}$ (35). The researchers in this study found that the percent of $25(\mathrm{OH}) \mathrm{D}_{2}$ contribution to total $25(\mathrm{OH}) \mathrm{D}$ was higher in the winter $(35 \%)$ 
than in the summer $(16 \%)(35)$. There were no age-related differences in serum $25(\mathrm{OH}) \mathrm{D}$ levels between the subjects, and these levels corresponded with normal values (35). Normal serum 25(OH)D levels range from 8 to $60 \mathrm{ng} / \mathrm{mL}$, with an average of 25 to 30 $\mathrm{ng} / \mathrm{mL}$ (23). Less than $10 \mathrm{ng} / \mathrm{mL}$ is considered deficient (23).

A greater seasonal variation in the serum $25(\mathrm{OH}) \mathrm{D}$ levels of children was seen in countries where milk is not fortified with vitamin D, including England $(10,14)$, France (11,15), Spain (12), and Argentina (13). For example, Docio et al. (12), studied the seasonal variation of serum 25(OH)D levels in mentally retarded children in Spain, ages 7 to 10 years old. March levels $(12.6-5.5 \mathrm{ng} / \mathrm{ml})$ were significantly lower than October levels $(29.99 .4 \mathrm{ng} / \mathrm{ml})$. A cross-sectional study of 94 normal children in the same locale showed the same variation. Dietary vitamin $\mathrm{D}$ intake only had a significant effect on $25(\mathrm{OH}) \mathrm{D}$ levels in the winter, not in the summer. Average vitamin $\mathrm{D}$ intakes were $72 \bullet 24$ IU/day for the mentally retarded children and $160 \bullet 80 \mathrm{IU} /$ day for the normal children. At the time of this research, milk was not fortified with vitamin D in Spain (12). The same seasonal variation in serum $25(\mathrm{OH}) \mathrm{D}$ levels was found in a study of adolescent boys in France (11). September levels were higher at $29.96 \pm 7.46 \mathrm{ng} / \mathrm{ml}$ compared to March levels of $6.61 \bullet 2.04 \mathrm{ng} / \mathrm{ml}$. Dietary vitamin D intake levels were not determined.

As serum 25(OH)D levels decrease in winter, an increase in serum PTH has been reported in numerous studies of postmenopausal women and elderly men $(4,7,36)$. Impaired calcium absorption associated with reduced vitamin D status causes increased PTH production in order to mobilize calcium from the skeleton to maintain normal serum calcium levels $(18,22,24)$. Thus, an increased PTH level due to vitamin D inadequacy, 
termed secondary hyperparathyroidism, is a contributing factor to bone loss in the elderly $(4,7,36,37,38)$.

Rosen et al. (7) found a seasonal drop in serum 25(OH)D levels and an elevation in PTH levels in postmenopausal women in Greenville, Maine during the winter which correlated with increased bone loss. During the summer, when serum 25(OH)D increased and PTH decreased, bone mineral density (BMD) of the spine and hip remained constant or slightly increased. In the second year of the study when vitamin D intake increased by $30 \%, \mathrm{BMD}$ increased in the summer and remained the same in the winter.

There are very little data on PTH concentrations in children, but Guillemant et al. (11) found a significant increase in PTH by a mean of $8.59 \pm 8.53 \mathrm{ng} / \mathrm{L}$ corresponding to a decrease in serum 25(OH)D during the winter. Although the PTH levels remained within normal limits, the authors expressed concern regarding seasonal elevations in PTH, suggesting a suboptimal supply of vitamin D which may keep a growing child from achieving peak bone mass.

A severe vitamin $\mathrm{D}$ deficiency in children results in rickets, a disease occurring when bones are growing and there is insufficient mineralization of the skeleton. Bones become deformed. In adults, an insufficient availability of vitamin $\mathrm{D}$ impairs intestinal calcium absorption. Demineralization of the bone matrix causes osteomalacia, softening of the bone (18).

Even if deficiency levels to cause rickets or osteomalacia are not met, less severe vitamin $\mathrm{D}$ deficiency may lead to secondary hyperparathyroidism resulting in increased bone turnover, bone loss, and increased risk of fracture (4,7,36-38). Little is known about the effect of seasonal reductions in vitamin D status on bone health in children and adults. 
Woitge et al. (39) analyzed markers of bone turnover in a population of adults in Germany, ages 50 to 81 years. They determined that, except for age, season had a larger effect on bone turnover than any other factor studied, with decreased serum $25(\mathrm{OH}) \mathrm{D}$ levels and increased bone turnover occurring in the winter. Jones et al. (40) found that sunlight exposure was significantly associated with bone mineral density in the hip and spine in Australian children, especially the girls, although serum 25(OH)D levels were not measured. Winters could be a concern for residents of Maine and other northern locales. Factors contributing to reduced vitamin D synthesis include spending less time outside, wearing more clothing, and the reduced UVB rays reaching the earth's surface.

Suboptimal vitamin D status may put adolescent girls in Maine at risk for not reaching their optimal peak bone mass. Adults who work indoors and the elderly may be at risk for an increased rate of bone loss because of sub-optimal vitamin D status.

\section{Sun-Exposure Questionnaire Development}

\section{$\underline{\text { Rationale }}$}

There is a strong correlation between sun exposure and serum $25(\mathrm{OH}) \mathrm{D}$ levels, the best indicator of overall vitamin D status. Malvy et al. (41) recently analyzed serum 25(OH)D levels of 1191 adults in France to determine the connection between melanin content of skin and vitamin D status. This study found that the main determinant of vitamin D status was not skin phototype, but the degree of sun exposure and latitude of residence. Even though people with fair skin can more easily synthesize vitamin $D$ than darker skinned people, the lighter skinned subjects in this study had lower serum $25(\mathrm{OH}) \mathrm{D}$ levels because they spent less time in the sun (41). Dietary vitamin D intake was not monitored, but the authors assumed all subjects had low intake because milk is not fortified 
with vitamin D in France (41). Jones et al. (42) found that sunlight exposure was the major determinant of 25(OH)D levels in a population of 8-year-old children in Southern Tasmania, Australia. Mean dietary vitamin D intake was low (40 IU/day) and was not associated with serum $25(\mathrm{OH}) \mathrm{D}$ levels. Serum $25(\mathrm{OH}) \mathrm{D}$ levels were the highest in this group in the months following school vacations (42). In a study of elderly subjects in the Netherlands, subjects with the lowest sun exposure had the lowest serum 25(OH)D levels. The mean dietary intake in both groups was low $(115 \mathrm{IU} / \mathrm{d})(19)$.

In a population of women aged 20 to 80 in lowa, $25(\mathrm{OH}) \mathrm{D}$ levels were more closely correlated with estimated sun exposure $(r=0.26)$ than estimated dietary intake $(r=11)(43)$. Webb et al. (8) determined that residents of a nursing home in Boston had decreased sun exposure which required vitamin D supplementation to maintain $25(\mathrm{OH}) \mathrm{D}$ levels, whereas free-living elderly who went outdoors were better able to maintain $25(\mathrm{OH}) \mathrm{D}$ levels within normal limits.

Because sunlight exposure has a major impact on serum vitamin D status, especially with sub-optimal dietary vitamin D intake, an instrument that can stratify individuals into groups based on relative skin synthesis of vitamin $D$ would be useful for many studies of vitamin D status and bone mineralization.

\section{Previous Attempts}

Sun-exposure questionnaires have been developed in previous studies of vitamin D status of adult and elderly populations $(6,19,43)$. These questionnaires were not validated and did not take into consideration the varying strength of UVB rays throughout the day. Lips et al. (19) devised a questionnaire based on two categories of time spent outside, little or frequent. Combining this information with reported sun exposure level (high or low) 
while outside generated a sunshine score of three categories: low, intermediate, or high. Salamone et al. (6) used this method in combination with another questionnaire that asked subjects to report time spent outside and sunscreen use during the previous week. These questionnaires were used to stratify the sun exposure levels of healthy elderly women according to a score of one to nine. The time of day was not considered.

Sowers et al. (43) ranked a population of Iowa women according to a sun-exposure score. A self-reported sunlight whole-body equivalent was determined based on hours spent outside each day adjusted for the percentage of body surface area exposed. Sunscreen use was a factor for this questionnaire, but again, time of day was not considered.

Jones et al. (40) used a sun-exposure questionnaire in a population of eight-yearold children to determine the relationship between bone mass and sunlight exposure in Tasmania, Australia $\left(42^{\circ} \mathrm{S}\right)$. The questionnaire asked the subjects to report the number of hours per day spent outdoors. The categories where limited to four broad spans of time, the minimum being less than two hours and the maximum was categorized as more than four hours. These same researchers validated two questionnaires of habitual sun exposure against polysulphone (PS) badges in a population of teenagers (14-15 years old) in Australia (44). The questionnaires were administered over a four-month period. Questionnaire One asked subjects to report usual sun exposure, focusing on time spent outside on weekends, history of sunbathing, and vacations to sunny destinations. Questionnaire Two focused on the previous summer vacation and was activity-based, asking questions regarding time and frequency of sun-based activities. Six months later, the subjects wore PS badges on four days over two consecutive weekends and kept an 
activity diary for each of those days. Information in the daily diaries was grouped into three categories of general location during the morning and afternoon of each study day: inside, outside in the shade, and outside in the sun. The best correlation occurred when the badge readings were compared with the daily diaries. The correlation was 0.42 (girls) and 0.57 (boys) for all four days. The correlation was not as strong between Questionnaires One and Two and the PS badge readings. The strongest correlation occurred with questions regarding time in the sun $(r=0.38)$ and time spent outdoors $(r=0.32)$ during weekends and holidays. Other questions showed little or no correlation, indicating that habitual sun exposure is difficult to validate (44).

Factors to Consider in Questionnaire Design Population

The same difficulties in assessing self-reported sun exposure in children are seen in assessing physical activity levels in children. Measurements of these two parameters can be compared because both are activity based and many activities occur outdoors, especially during the summer when UVB strength is the strongest. Thus, characteristics of children that determine the most reliable method for measuring usual physical activity levels are presumed to be similar to characteristics that determine the best method for assessing usual sun exposure. As there is little information available on methodologies for assessing sun exposure in children, research on physical activity assessment in children was used in designing the sun-exposure questionnaire.

A sun-exposure history was not used because children may have a difficult time recalling activity over long periods of time. Sallis et al. (45) assessed the reliability and validity of different self-reporting physical activity questionnaires administered to children 
in the fifth to eleventh grade. It was found that the length of the time between activity and recall clearly affected reliability. The researchers determined that recall of physical activity was optimal the day following the activity and repeated 24-hour recalls would be the most reliable method to use with this age group.

Even when using 24-hour recalls, Sallis et al. (46) determined in another study of fifth grade students that children did not accurately recall absolute minutes. Physical activity checklists were validated against accelerometers and heart rate monitors. The researchers concluded that a self-reported 24-hour recall of physical activity was useful in stratifying subjects according to relative amounts of physical activity (46). Going et al. (47) also administered 24-hour recall questionnaires in a checklist format in a pilot study of physical activity assessment of American Indian children. The problem with a checklist format is that most children have a wide range of activities $(48,49)$ and a checklist format may be too cumbersome and too long for a child's attention span if it included all possible activities.

Simons-Morton et al. (48) validated a physical activity recall with heart rate monitors in a population of third and fifth grade students. These researchers also found that children did not accurately recall absolute minutes, as they tended to over-report minutes spent exercising during an activity. It was found that the fifth graders were more accurate than the third graders. The authors recommended multiple 24-hour recalls to obtain a reasonable assessment of a child's physical activity.

Based on the above findings, the sun-exposure questionnaire developed here was administered to a population of adolescent girls as a 24-hour recall because of the great variation in day-to-day activities of young children and their difficulties with long term 
recall. Because adults tend to follow a typical schedule revolving around work and other responsibilities, and have greater cognitive function, they probably are better able to recall or report usual behavior. This questionnaire could easily be adapted to use with adults to report usual time spent in the sun over periods of weeks or months.

UVB Variation

As stated earlier, latitude, season and time of day have a tremendous effect on the potential for cutaneous vitamin D synthesis because of the varying strengths of UVB photons reaching the earth. The plot of UVB radiation on cloudless days approximates a bell-shaped curve, reaching the highest point mid-day and dropping off on either side (see Appendix B). The hourly formation of previtamin $\mathrm{D}_{3}$ coincides with the UVB curve (29) (Appendix A). Because of the hourly variation in UVB strength, it is important to quantify minutes spent outdoors at different times throughout the day and correct for the strength of the sun's rays. In analyzing results from this questionnaire, each hour of the day is assessed as a fractional equivalent of mid-day sun, the time of peak UVB strength and peak vitamin D synthesis. Subjects are only asked to report sun exposure occurring outdoors because glass and plastics absorb UVB photons. Exposure to sunlight through glass and plastic windows does not produce vitamin D synthesis in the skin (2).

Body Surface Area Exposed

Clothing (50) and sunscreen lotions (51) suppress or prevent cutaneous vitamin D production by absorbing UVB photons. An application of lotion containing paraaminobenzoic acid (PABA), which has a sun protection factor of eight, was found to effectively block the conversion of 7-DHC to previtamin $\mathrm{D}_{3}(51)$. PABA has an action spectrum of $240-400 \mathrm{~nm}$ (51), meaning it absorbs photons in this wavelength range, which 
includes the wavelengths responsible for vitamin D synthesis. Thus, for research applications, the sun-exposure questionnaire includes a section to describe clothing worn and sunscreen use to estimate body surface area exposed to the sun. Along with total corrected minutes in the sun, these variables would be entered into statistical analysis to stratify subjects based on the potential for skin synthesis of vitamin D.

\section{Summary}

In conclusion, due to the great impact of sun exposure on vitamin D status, it is inadequate and impractical to quantify vitamin $\mathrm{D}$ intake by looking at diet alone. If a person has at least some sun exposure, then cutaneous vitamin D synthesis must be considered in determining total vitamin D intake. It is difficult to assess sun exposure in relation to vitamin $\mathrm{D}$ synthesis because of the many environmental and behavioral factors that affect vitamin D synthesis in the skin. Previous attempts to quantify sun exposure have not adequately addressed the environmental factors. Furthermore, there have been few attempts to test or validate sun exposure questionnaires. The objectives of this study were to:

1. Develop a sun-exposure questionnaire that accounts for the strength of UVB rays during sun exposure as well as total length of sun exposure.

2. Test this questionnaire in a sample of adolescent girls by comparing self-report of sun exposure via questionnaire to an objective measure of sun exposure.

3. Utilize an in vitro model of previtamin $\mathrm{D}_{3}$ synthesis to estimate the physiologic level of vitamin D synthesis during each hour of the day on a summer day in Maine. 


\section{MATERIALS AND METHODS}

\section{Study Design}

Thirty-five adolescent girls each wore a polysulphone (PS) badge and kept an activity $\log$ for one day on August 17, 2001. A questionnaire was administered the following day, asking the subjects to recount the previous day from their activity records, specifically time spent outdoors. Minutes spent outdoors during each hour of the day were corrected for the strength of the UVB rays during that hour. A score of total adjusted minutes outside was determined for each subject. This score was compared with the measurement of UVB exposure obtained from the PS badges. PS badges were also exposed in an unshaded region on a flat surface to gauge ambient levels of UVB radiation for each hour of the day. Simultaneously, 7-DHC ampules were exposed to give an unequivocal measure of maximum previtamin $D_{3}$ synthesis during each hour of the day.

\section{Subjects and Recruitment}

The 35 subjects for this study included girls aged 9-11 years previously recruited for a longitudinal study of bone mineralization rates, plus a subset of girls, aged 9-15 years, who were recruited for this study only. All subjects resided in the region of Bangor, Maine (latitude $44^{\circ} 48^{\prime} \mathrm{N}$ ). Inclusion in the study required that the subjects be capable of spending time outdoors. A parent or guardian of each subject signed an informed consent form that outlined the study. Verbal assent was obtained from each subject. See Appendix C for copies of the consent and assent forms. The Human Subjects Review Board at the University of Maine approved the study protocol. 


\section{Materials and Instruments}

\section{Polysulphone (PS) Film Dosimeters}

Polysulphone film is a photosensitive polymer film used as part of a small badge attached to an individual's clothing to measure UVB exposure. PS film has been used as a personal dosimeter to quantify UVB exposure for studying the etiology of skin cancer $(52,53)$, ophthalmic disease $(54)$, and vitamin D status $(7,8)$. Ultraviolet radiation from the sun causes deterioration of PS film that increases the film's absorption of ultraviolet rays (increased optical density). Polysulphone has an action spectrum that peaks at $300 \mathrm{~nm}$ and drops off to $1 \%$ at $330 \mathrm{~nm}$ (55). The absorbance of the PS film changes when it is exposed to wavelengths less than $330 \mathrm{~nm}$. Thus, the PS film is used to monitor broadband UVB radiation (290-320 $\mathrm{nm}$ ) by measuring the degree of change. Pre-exposure optical absorbance of the film is read by a spectrophotometer set at $330 \mathrm{~nm}$. Post-exposure, the film is read according to the same protocol to determine the change in optical absorbance $(\Delta A)(56)$. The dose-response curve of PS film is not linear, although it approximates a linear response until the $\Delta \mathrm{A}$ approaches saturation. The response of the PS film decreases significantly at $\Delta \mathrm{A}>0.3(55)$.

Polysulphone film is used in studies of ultraviolet exposure because it is sensitive to the same wavelengths that affect human skin. PS film calibrated to the solar spectrum has been used to obtain quantitative measurements of personal sun exposure (54). However, the response spectrum of PS badges extends into longer wavelengths than the action spectrum of cutaneous vitamin D photosynthesis (55). Because the film's sensitivity extends to wavelengths up to $330 \mathrm{~nm}$, and vitamin D synthesis ceases at wavelengths greater than $315 \mathrm{~nm}$, this can lead to errors when using PS film for objective measures of 
effective UVB for vitamin D synthesis. However, the PS film is useful for obtaining relative UVB exposures for each subject (57). The error in the usage of PS film as UV dosimeters is of the order of $\pm 10 \%$. This includes all the errors in the usage, fabrication and calibration of the film (personal correspondence, Alfio Parisi, $\mathrm{PhD}$, University of Southern Queensland, December 19, 2000). The PS film for this study was manufactured and analyzed at the Centre for Astronomy and Atmospheric Research at the University of Southern Queensland (USQ), Toowoomaba, Queensland, Australia.

\section{7-DHC in Ethanol}

Borosilicate glass ampules containing $35 \mathrm{mg}$ of 7-DHC $(50 \mu \mathrm{g} / \mathrm{ml})$ (Salsbury Laboratories Inc., Charles City, Iowa) in $0.7 \mathrm{ml}$ of ethanol were sealed under argon. The ampules were exposed to natural sunlight each hour from $6 \mathrm{AM}$ to $7 \mathrm{PM}$ and at other combinations of time throughout the day in Orono, ME. After the exposure, the samples were shipped to Boston under refrigeration and then stored at $-20^{\circ} \mathrm{C}$ or $-70^{\circ} \mathrm{C}$ until the samples were analyzed by high performance liquid chromatography (HPLC) as described (3). Briefly, at the time of analysis, aliquots $(200 \mu \mathrm{l})$ were removed from each ampule, transferred into glass test tubes, and dried under a stream of nitrogen gas. Two hundred $\mu \mathrm{l}$ of $0.6 \%$ isopropyl alcohol in $n$-hexane were then added to redissolve the samples. The redissolved samples were applied to high performance liquid chromatography (Waters, Milford, MA) equipped with a fixed wavelength UV detector (254 nm). The conditions for HPLC were as follows: column, Econoshere silica, $5 \mu, 250$ x $4.6 \mathrm{~mm}$ (Alltech Associate Inc. Deerfield, Il); mobile phase, $0.6 \%$ isopropyl alcohol in n-hexane; and flow rate, 1.8 $\mathrm{ml} / \mathrm{min}$. The concentrations of $7-\mathrm{DHC}$ and $\mathrm{preD}_{3}$ were determined with the external 
standards. The limit of detection is $0.04 \%$ for pre $\mathrm{D}_{3}, 0.07 \%$ for lumisterol, $0.03 \%$ for tachysterol, and $0.02 \%$ for Vitamin $D_{3}$.

Conversion of pre $D_{3}$ to $D_{3}$ is heat dependent (25) and this thermal isomerization occurs while the ampules are exposed to the heat of the sun. In ampule analysis, the total percent pre $\mathrm{D}_{3}$ formed is computed and reported as a combination of percent pre $\mathrm{D}_{3}$ and percent $D_{3}$. Lumisterol is reported as percent lumisterol present in the ampule solution.

Results obtained from the ampules represent maximal possible conversion of 7 . DHC to previtamin $D_{3}$. The previtamin $D_{3}$ synthesis occurring in human skin would be less than in the ampules because human skin contains UVB-absorbing substances other than 7-DHC (31). Subtracting $0.8 \%$ from $\mathrm{preD}_{3}$ detected in ampules estimates the percent pre $\mathrm{D}_{3}$ that would occur in a skin sample (58). These ampules were provided by and analyzed at the Vitamin D, Skin and Bone Research Laboratory, Boston University School of Medicine, Boston, Massachusetts.

\section{UVB Pyranometer}

To Determine the Hourly UVB Correction Factor

Broadband UVB data from the USDA UVB monitoring station in Presque Isle, Maine $\left(46.7^{\circ} \mathrm{N}\right)$ was used to determine the fractional equivalent of peak UVB strength for each hour of the day. The Natural Resource Ecology Laboratory at the University of Colorado maintains the UVB pyranometer at the monitoring station. A pyranometer is an instrument used to measure specific wavelengths of ultraviolet radiation reaching the earth. The broadband UVB-1 pyranometer in Presque Isle (Yankee Environment Systems) measures in the spectral range of $280-330 \mathrm{~nm}$. Voltage readings of solar energy are

converted to units of watts per square meter (watts $/ \mathrm{m}^{2}$ ). Measurements of UVB in watts $/ \mathrm{m}^{2}$ 
are recorded by the pyranometer every fifteen seconds. Three-minute averages of these measurements are available to download from the USDA UVB Monitoring Station Web Site at http://uvb.nrel.colostate.edu/UVB climate network.htm. The mean UVB for each hour of the study day in August was determined from the three-minute averages. The hour with peak average UVB was determined. The fractional equivalent of peak for each hour of the day was determined by dividing the average hourly UVB by the peak average UVB to determine percent of peak for each hour of the day.

To Compare Specific Wavelengths in Winter vs. Summer

A pilot test of the August study was conducted in February 2000. Badge and ampule results from one hour on February 22, 2000 were compared with badge and ampule results during one hour of similar UVB levels on the August study day. The optimum wavelengths for pre $D_{3}$ synthesis in the skin are the shorter wavelengths between 295-300 $\mathrm{nm}$, with maximum pre $\mathrm{D}_{3}$ synthesis occurring around $297 \mathrm{~nm}$ (33). By obtaining the UVB spectral data for two points of time with an equivalent UVB level in the winter and in the summer, it is possible to compare the relative strengths of different wavelengths during these times. Researchers at the UDSA UVB Monitoring Program at Colorado State University provided the data for the entire spectrum from $295-316 \mathrm{~nm}$ in $0.1 \mathrm{~nm}$ intervals for two points of time, one on February 22 and one on August 17, which had equivalent broadband UVB levels. This spectral data was recorded by the pyranometer in Presque Isle, but was not available over the Internet. Measurements at each wavelength were averaged. For example, measurements of $295.0-295.9 \mathrm{~nm}$ were averaged to obtain the average measurement of irradiation at $295 \mathrm{~nm}$. 


\section{Study Protocol}

\section{Subject Procedures}

In August, 2000, 35 subjects, accompanied by a parent, met with the principle investigator. Each girl was given a polysulphone (PS) badge sealed in a radio opaque container and instructions to wear the PS badge during all waking moments of the study day (August 17, 2000). See Appendix D for the Badge Instruction Sheet given to each subject. All of the subjects wore the badges on the same day so that they were exposed to the same local climate conditions.

The subjects were instructed to adhere the PS badge to the front upper left-hand corner of their shirt or coat on August 17, 2000. Each film badge was constructed by mounting PS film on $3 \mathrm{~cm} \times 3 \mathrm{~cm}$ white plastic holders with a central aperture. The badges were attached to clothing by a safety pin attached to a string that ran through a hole in the cardboard holder. The badges were attached so that only one side of the badge was exposed. Subjects were able to attach and remove badges from their clothing with ease. It was emphasized that the PS badge should be exposed to the sunlight only when the subjects are outdoors. Subjects were encouraged to carry out their usual daily activities. At the end of the day, subjects placed the PS badge in the provided light-proof container. The following day, each subject completed a sun-exposure questionnaire administered over the telephone by the principle investigator, her advisor, Susan Sullivan, DSc, RD, or another research assistant. All subjects returned the badges in the light-proof container to the University of Maine via self-addressed stamped envelope. Pre-exposure, the optical absorbance of the badges was measured at $330 \mathrm{~nm}$ with a spectrophotometer at USQ. The 
change in absorbance of each dosimeter was determined by post-exposure measurement with the same spectrophotometer set at $330 \mathrm{~nm}$.

Administration and Analysis of Sun-Exposure Questionnaire

The administrator of the sun-exposure questionnaire asked each subject to recall all activities on the study day. Using the activity records they kept on the study day, the subject reported hours or minutes spent outside during each hour of the day between 6 AM and 7 PM. Copies of the activity worksheet used by each subject and the sun-exposure questionnaire administered over the telephone are shown in Appendix E.

For each subject, reported minutes in the sun for each hour were multiplied by that hour's fractional equivalent of peak hour UVB to obtain total minutes spent outside corrected to a standard of peak UVB. For example, on August 17, 2000, the average hourly UVB strength between $2 \mathrm{PM}$ and $3 \mathrm{PM}$ in the afternoon was $46 \%$ of the strength between 11 AM and noon (see Appendix F). Minutes spent outside between 2 PM and 3 PM during this day were multiplied by 0.46 in order to standardize the minutes. Correcting the minutes spent outdoors for the strength of the sun can result in a substantially different number than total minutes spent outdoors (See Appendix G).

\section{$\underline{\text { In Vitro Measurements }}$}

On the study day, August 17,2000 , two PS badges were exposed on a flat surface in an unshaded area in Orono during each hour of the day between the hours of $6 \mathrm{AM}$ and 7 PM. The badge exposure for each hour was determined by averaging the $\Delta \mathrm{A}$ of the two badges. To determine ambient exposure for the day, four badges were also exposed all day from 6 AM to 7 PM. Ampules with 7-DHC solution were placed on the same tray holding 
the PS badge dosimeters and were exposed following the same protocol as the badges. Hourly weather conditions were documented in Orono and in Presque Isle.

In Presque Isle, the location of the UVB pyranometer, a series of 28 PS badges were exposed at $8 \mathrm{AM}$ and two were removed every half hour until $3 \mathrm{PM}$. A calibration curve was determined by relating the $\Delta A$ of the series of badges to cumulative UVB values each badge was exposed to, read from the UVB pyranometer. The calibration curve can be used to determine UVB exposure of other badges exposed during the same day. The absolute cumulative UVB dose a badge has been exposed to can be determined by plugging in the $\Delta \mathrm{A}$ of the badge to the equation generated from the calibration curve.

\section{Statistical Analysis}

The statistical analysis was conducted using the Data Analysis ToolPac in Microsoft Excel, 2000 edition. Pearson correlation coefficients were determined between subject corrected minutes outdoors and PS badge readings. Correlation coefficients were also determined between various variables including badge readings and $\mathrm{preD}_{3}$ production in ampules exposed on a horizontal plane and UVB levels. Paired student t-tests were used to compare badges exposed in Presque Isle vs. Orono and minutes corrected based on UVB data on the study day vs. a sunny day in August. 


\section{RESULTS}

\section{Subject Results}

The study sample consisted of 35 girls between the ages of 9 and 15 years.

Mean age \pm standard deviation (SD) of the participants was $11.97 \pm 1.85$ years. All 35

subjects successfully completed the study. The means ( \pm SD) of total time spent

outdoors and minutes outdoors corrected for the time of day were $170.97( \pm 124.09)$ and

$87.36( \pm 70.55)$ minutes, respectively. The mean PS badge reading (change in

absorbance $(\Delta \mathrm{A}))$ was $0.086( \pm .07)$, see Table 1 . The correlation coefficient between subject corrected minutes outdoors and badge readings was $0.71(p=0.000)$. The scatter plot and regression line fit by least squares is depicted in Figure 1. The corrected minutes spent outdoors reported by the older subjects, ages $12-15$, had a stronger correlation with badge readings than that of the younger subjects, ages 9-11 (Table 2). There was a stronger correlation when reported time spent outdoors was corrected for hourly UVB strength $(r=0.71)$ then when total reported minutes were compared with subject badge readings $(r=0.64)$ (Table 1$)$. 
Table 1

Subject Self-Reported Time Outdoors and PS Badge Results

\begin{tabular}{|c|c|c|c|}
\hline Subject ID\# & $\begin{array}{l}\text { Total Minutes } \\
\text { Outdoors }\end{array}$ & $\begin{array}{l}\text { Corrected Minutes } \\
\text { Outdoors }\end{array}$ & $\begin{array}{c}\text { Badge Reading } \\
(\Delta \mathbf{A})\end{array}$ \\
\hline 4 & 0 & 0 & 0.015 \\
\hline 3 & 5 & 0.2 & 0.005 \\
\hline 10 & 10 & 3 & 0.014 \\
\hline 35 & 62 & 3.32 & 0 \\
\hline 1 & 4 & 3.92 & 0.023 \\
\hline 11 & 8 & 4.16 & 0.027 \\
\hline 9 & 99 & 8.41 & 0.036 \\
\hline 16 & 34 & 15.12 & 0.011 \\
\hline 12 & 20 & 15.3 & 0.007 \\
\hline 29 & 22 & 22 & 0.019 \\
\hline 14 & 134 & 37.07 & 0.034 \\
\hline 18 & 125 & 38.8 & 0.028 \\
\hline 22 & 140 & 57.06 & 0.165 \\
\hline 32 & 156 & 60.66 & 0.021 \\
\hline 21 & 100 & 62.5 & 0.068 \\
\hline 23 & 104 & 67.19 & 0.181 \\
\hline 33 & 126 & 73.17 & 0.053 \\
\hline 17 & 245 & 88.65 & 0.014 \\
\hline 15 & 162 & 93.14 & 0.038 \\
\hline 31 & 238 & 96.09 & 0.154 \\
\hline 20 & 230 & 98.82 & 0.1 \\
\hline 19 & 193 & 101.51 & 0.091 \\
\hline 13 & 180 & 102.3 & 0.073 \\
\hline 8 & 236 & 109.55 & 0.132 \\
\hline 7 & 236 & 117.19 & 0.149 \\
\hline 28 & 275 & 119.15 & 0.1 \\
\hline 27 & 249 & 129.94 & 0.201 \\
\hline 26 & 193 & 141.74 & 0.253 \\
\hline 6 & 305 & 172.35 & 0.146 \\
\hline 2 & 205 & 178.2 & 0.114 \\
\hline 24 & 275 & 190.95 & 0.158 \\
\hline 5 & 395 & 193.6 & 0.159 \\
\hline 34 & 380 & 197.65 & 0.08 \\
\hline 30 & 383 & 210.99 & 0.244 \\
\hline 25 & 455 & 243.95 & 0.107 \\
\hline in (SD) & $170.97(124.09)$ & $87.36(70.55)$ & $0.086(.07)$ \\
\hline 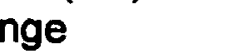 & $0-455$ & $0-243.95$ & \\
\hline rrelation with & $0.64^{\star}$ & $0.71^{*}$ & \\
\hline don (r) & & & \\
\hline 100 & & & \\
\hline
\end{tabular}


Figure 1: Subject Corrected Minutes Outdoors vs. Badge Reading Orono August 17, 2000

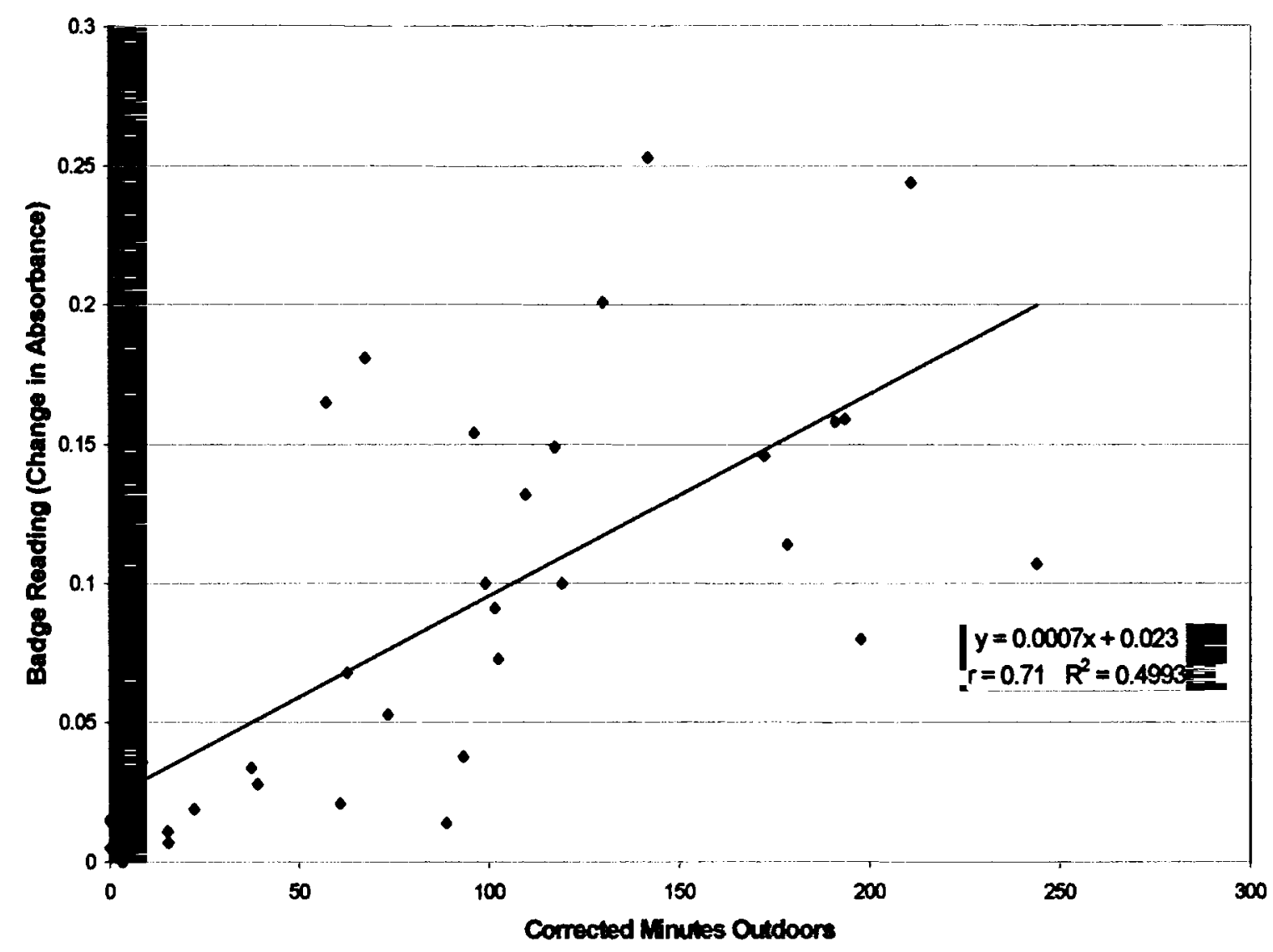

\section{Table 2}

Correlation Between Corrected Minutes

Outdoors and Badge Readings by Age

\begin{tabular}{cc} 
Age & Correlation \\
\hline $9-11(\mathrm{n}=15)$ & $0.62(\mathrm{p}<0.05)$ \\
$12.15(\mathrm{n}=20)$ & $0.79(\mathrm{p}=0.000)$ \\
\hline
\end{tabular}

Validity of the Hourly Correction For Relative UVB Strength

\section{Badges Exposed on Horizontal Plane}

The change in absorbance of badges exposed on a horizontal plane in Orono is plotted against the minutes of exposure for each badge, corrected for the strength of the 
sun, in Figure $2(r=0.96)$. The regression line shows that corrected minutes can predict a badge reading when the badges are exposed on a horizontal plane $\left(\mathrm{R}^{2}=0.95\right)$.

Figure 2: Corrected Minutes vs. Badge Reading (Horizontal Plane)

Orono August 17, 2000

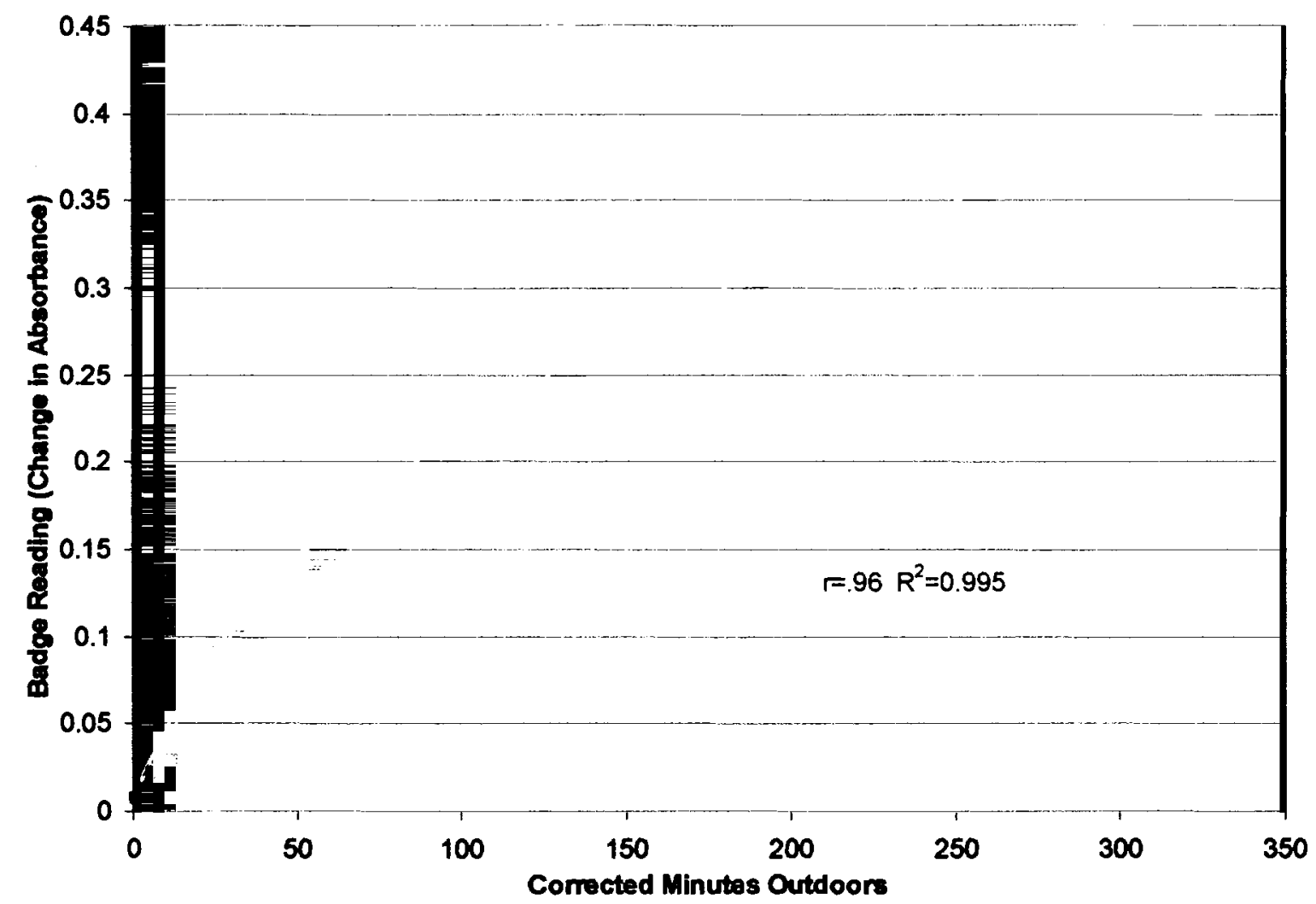

\section{Effect of Cloud Cover on Correction Factor}

Variable cloudiness, periods of heavy clouds interrupted with periods of sun, occurred on the study day (August 17, 2000). As a result, the UVB plot obtained from the pyranometer in Presque Isle for the study day showed marked variability in UVB intensities over the course of the day (Appendix B). To examine the impact of weather on the correction factors, subject reported minutes outdoors were also corrected using factors derived from a sunny day, nine days after the study day. Table 3 depicts the 
average UVB levels during each hour of the day and the hourly correction factors for the study day and the cloudless day in August.

Table 3

UVB Data and Hourly Percent of Peak of Two Days in August

\begin{tabular}{|c|c|c|c|c|}
\hline & Presqu & $\begin{array}{l}\text { le, } 08 / 17 / 2000 \\
\text { dy Day) }\end{array}$ & $\begin{array}{l}\text { Presqui } \\
\text { (Clc }\end{array}$ & $\begin{array}{l}\text { le, 08/26/2000 } \\
\text { less Day) }\end{array}$ \\
\hline Time & Average & Percent of the & Average & Percent of the \\
\hline & UVB & Peak & UVB & Peak \\
\hline 7-8 AM & 0.040246 & $\begin{array}{l}0.99 \% \\
2.83 \%\end{array}$ & $\begin{array}{l}0.032275 \\
0.176431\end{array}$ & $\begin{array}{l}1.59 \% \\
8.69 \%\end{array}$ \\
\hline 8-9 AM & 0.266861 & $18.75 \%$ & 0.486588 & $23.96 \%$ \\
\hline $9-10$ AM & 0.547301 & $38.45 \%$ & 0.95753 & $47.15 \%$ \\
\hline 10-11 AM & 0.767914 & $53.95 \%$ & 1.487226 & $73.23 \%$ \\
\hline 11 AM-12 PM & 1.423454 & $100.00 \%$ & 1.908763 & $93.99 \%$ \\
\hline 12-1 PM & 1.397182 & $98.15 \%$ & 2.030878 & $100.00 \%$ \\
\hline 1-2 PM & 1.304489 & $91.64 \%$ & 1.991714 & $98.07 \%$ \\
\hline 2-3 PM & 0.658591 & $46.27 \%$ & 1.639639 & $80.74 \%$ \\
\hline 3-4 PM & 0.72137 & $50.68 \%$ & 1.112412 & $54.77 \%$ \\
\hline 4-5 PM & 0.427942 & $30.06 \%$ & 0.604078 & $29.74 \%$ \\
\hline 5-6 PM & 0.13284 & $9.33 \%$ & 0.237734 & $11.71 \%$ \\
\hline 6-7 PM & 0.05263 & $3.70 \%$ & 0.050086 & $2.47 \%$ \\
\hline 7-8 PM & 0.00728 & $0.51 \%$ & 0.003346 & $0.16 \%$ \\
\hline
\end{tabular}

Correcting the subject reported minutes utilizing the hourly correction factor from UVB data on the sunny, cloudless day in August also strongly correlated with subject badge readings $(r=0.72)$. Table 4 shows the mean \pm SD of reported minutes outdoors corrected for the study day $(8 / 17 / 00)$ and the cloudless day $(8 / 26 / 00)$.

A paired $t$-test indicates that the means of corrected minutes using correction factors from two different days were significantly different $(p<0.001)$. 
Table 4

Comparison of Subject Minutes Outdoors Corrected for 8/17 (Study Day) and 8/26 (Cloudless Day)

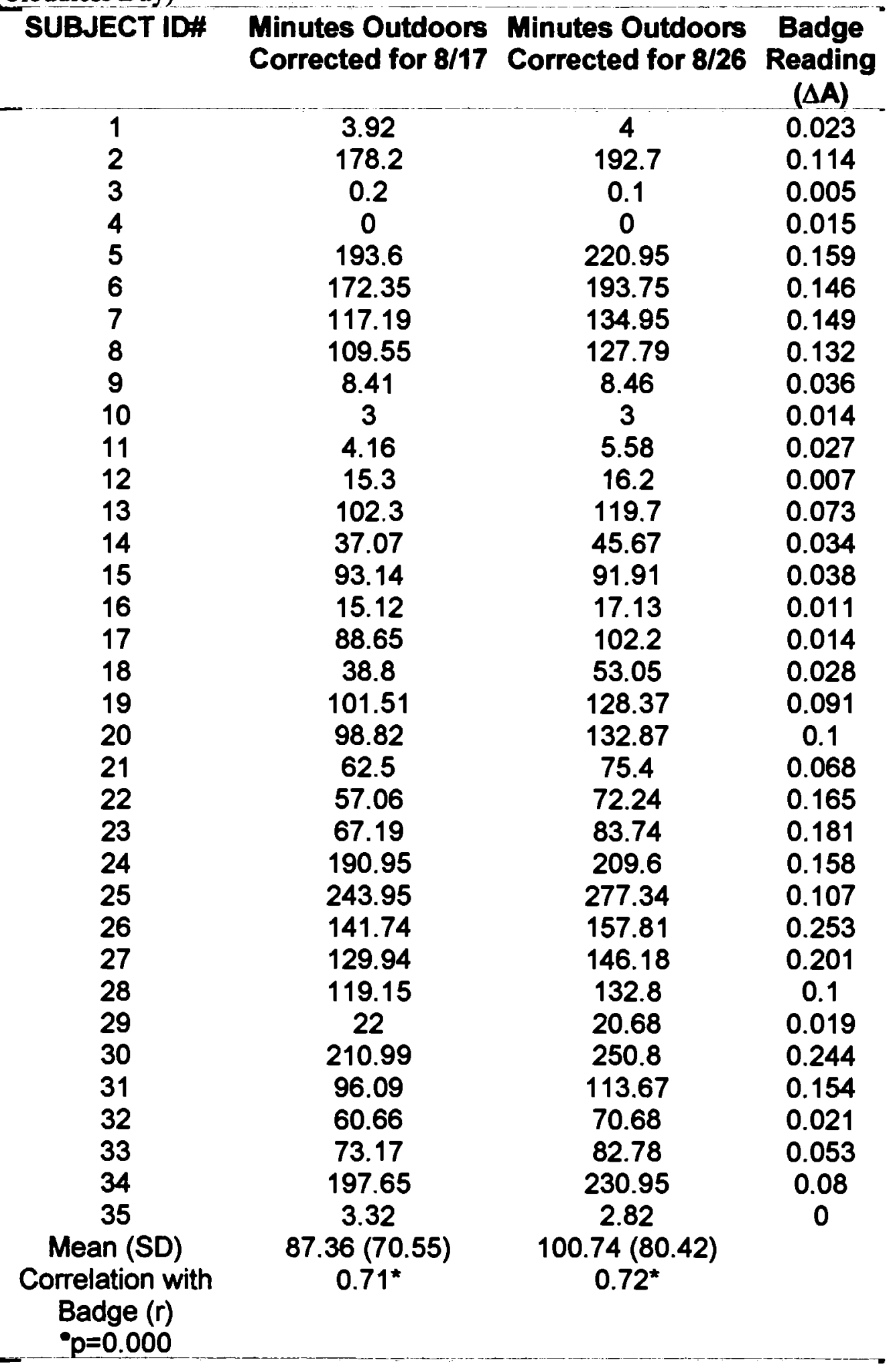




\section{In Vitro Results}

Association Between Strength of UVB Rays, Badge Results and Previtamin $\mathrm{D}_{3}$ Synthesis

Hourly badge readings and $\mathrm{preD}_{3}$ production in Orono, and the hourly UVB

levels recorded from the pyranometer in Presque Isle are plotted in Figure 3. Results of badges and ampules exposed during each hour of the day and all day (ambient) in Orono are summarized in Table 5. The greatest conversion of $7-\mathrm{DHC}$ to $\operatorname{preD}_{3}$ was $1.43 \%$, occurring between 12-1 PM. Average hourly UVB levels were strongly associated with percent PreD $_{3}$ production $(r=0.96)$ and badge readings $(r=0.95)$.

Table 5

Results of Badges and Ampules Exposed in Orono August 17,2000

\begin{tabular}{|c|c|c|c|c|c|c|c|}
\hline \multirow[b]{2}{*}{ Time of Day } & \multirow[b]{2}{*}{$\begin{array}{l}\text { Minutes } \\
\text { Exposed }\end{array}$} & \multirow[b]{2}{*}{$\begin{array}{l}\text { Corrected } \\
\text { Minutes }\end{array}$} & \multirow[b]{2}{*}{$\begin{array}{c}\text { Badge } \\
\text { Reading } \\
(\Delta A)\end{array}$} & \multicolumn{3}{|c|}{ Ampules } & \multirow[b]{2}{*}{$\begin{array}{c}\text { Average } \\
\text { UVB } \\
\text { (Presque } \\
\text { Isle) } \\
\text { (watt/m } \mathbf{m}^{\mathbf{2}}\end{array}$} \\
\hline & & & & $\begin{array}{c}\text { PreD }_{3}{ }^{*} \\
(\%)\end{array}$ & $\begin{array}{l}\mathrm{L}_{3} \\
(\%)\end{array}$ & $\begin{array}{c}\text { Estimated } \\
\text { Skin } \\
\text { Synthesis } \\
\text { (PreD, - } \\
(\%)\end{array}$ & \\
\hline $\begin{array}{c}\text { AMBIENT } \\
\text { 6-7 AM } \\
\text { 7-8 AM } \\
\text { 8-9 AM } \\
\text { 9-10 AM } \\
\text { 10-11 AM } \\
11 \text { AM-12 PM } \\
12-1 \text { PM } \\
1-2 \text { PM } \\
2-3 \text { PM } \\
\text { 3-4 PM } \\
\text { 4-5 PM } \\
\text { 5-6 PM } \\
\text { 6-7 PM }\end{array}$ & $\begin{array}{l}780 \\
60 \\
60 \\
60 \\
60 \\
60 \\
60 \\
60 \\
60 \\
60 \\
60 \\
60 \\
60 \\
60\end{array}$ & $\begin{array}{c}327 \\
0.6 \\
1.8 \\
11.4 \\
22.8 \\
32.4 \\
60 \\
58.8 \\
55.2 \\
27.6 \\
30.6 \\
18 \\
5.4 \\
2.4\end{array}$ & $\begin{array}{l}0.401 \\
0.008 \\
0.006 \\
0.032 \\
0.096 \\
0.106 \\
0.141 \\
0.176 \\
0.141 \\
0.12 \\
0.123 \\
0.07 \\
0.022 \\
0.012\end{array}$ & $\begin{array}{c}1.73 \\
0 \\
0 \\
0.135 \\
0.575 \\
1.02 \\
1.255 \\
1.43 \\
1.15 \\
0.985 \\
0.87 \\
0.41 \\
0.085 \\
0\end{array}$ & $\begin{array}{c}5.7 \\
0 \\
0 \\
0 \\
0.11 \\
0.265 \\
0.375 \\
0.455 \\
0.31 \\
0.28 \\
0.285 \\
0 \\
0 \\
0\end{array}$ & $\begin{array}{c}0.93 \\
0 \\
0 \\
0 \\
0 \\
0.22 \\
0.455 \\
0.63 \\
0.35 \\
0.185 \\
0.07 \\
0 \\
0 \\
0\end{array}$ & $\begin{array}{c}0.014071 \\
0.040246 \\
0.266861 \\
0.547301 \\
0.767914 \\
1.423454 \\
1.397182 \\
1.304489 \\
0.658591 \\
0.72137 \\
0.427942 \\
0.13284 \\
0.05263\end{array}$ \\
\hline
\end{tabular}

*Previtamin $\mathrm{D}_{3}=\%$ PreD $3+\% \mathrm{D}_{3}$

**Lumisterol

***6 AM-7 PM 
Figure 3: Relation of Hourly Badge Readings, Previtamin $D_{3}$ Formation and UVB Levels in Orono

August 17, 2000

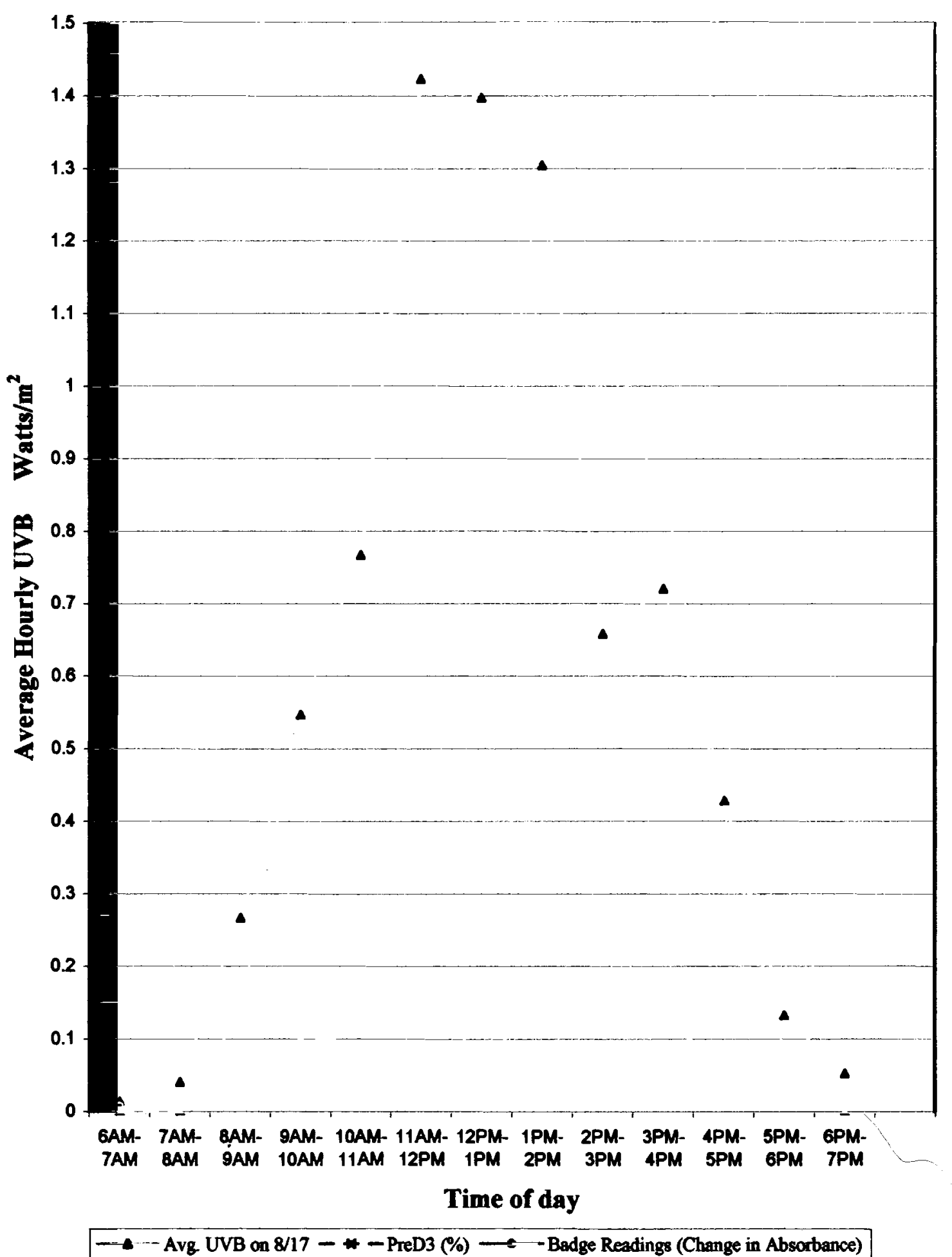


Effect of Length of UVB Exposure on Formation of Photoproducts From 7-DHC

Table 6 summarizes results of badges and ampules exposed in increments from 8 AM to 3 PM in Presque Isle. There was an increase in percent of photoproducts produced from the original 7-DHC in the ampules over time in Presque Isle from the start of exposure at $8 \mathrm{AM}$. Figure 4 represents the conversion of 7-DHC to photoproducts $\mathrm{PreD}_{3}$ and lumisterol in ampules, beginning at $8 \mathrm{AM}$ at half hour intervals. With continued exposure, the $\%$ preD $_{3}$ detected in the ampules began to plateau as conversion of pre $\mathrm{D}_{3}$ to lumisterol increased. In the series of ampules exposed from $8 \mathrm{AM}$ to $3 \mathrm{PM}$, the $\%$ pre $\mathrm{D}_{3}$ detected in the ampules began to plateau around 1:30 PM or 5.5 hours of exposure. A specific confidence interval of the time when the $\% \mathrm{preD}_{3}$ in the ampules began to plateau is not known because ampules were only removed at half hour intervals.

Table 6

Results of Badges and Ampules Exposed in Presque Isle August 17, 2000

\begin{tabular}{|c|c|c|c|c|c|c|}
\hline \multirow[b]{2}{*}{ TIME OF DAY } & \multirow[b]{2}{*}{$\begin{array}{c}\text { Total } \\
\text { Time } \\
\text { Exposed } \\
\text { (Hrs) }\end{array}$} & \multirow[b]{2}{*}{$\begin{array}{c}\text { Badge } \\
\text { Reading } \\
(\Delta A)\end{array}$} & \multicolumn{4}{|c|}{ Ampules } \\
\hline & & & $\begin{array}{c}\text { Pre } D_{3}^{*} \\
(\%)\end{array}$ & $\begin{array}{l}L_{3}^{* *} \\
(\%)\end{array}$ & $\begin{array}{c}\text { Total } \\
\text { Photoproducts } \\
(\%)\end{array}$ & $\begin{array}{c}\text { Skin } \\
\text { Synthesis } \\
\text { (PreD,-0.8) }\end{array}$ \\
\hline $\begin{array}{l}8 \text { AM-8:30 AM } \\
8 \text { AM-9 AM } \\
8 \text { AM-9:30 AM } \\
8 \text { AM-10 AM } \\
8 \text { AM-10:30 AM } \\
8 \text { AM-11 AM } \\
8 \text { AM-11:30 AM } \\
8 \text { AM-12 PM } \\
8 \text { AM-12:30 PM } \\
8 \text { AM-1 PM } \\
8 \text { AM-1:30 PM } \\
8 \text { AM-2 PM } \\
8 \text { AM-2:30 PM } \\
8 \text { AM-3 PM }\end{array}$ & $\begin{array}{c}0.5 \\
1 \\
1.5 \\
2 \\
2.5 \\
3 \\
3.5 \\
4 \\
4.5 \\
5 \\
5.5 \\
6 \\
6.5 \\
7\end{array}$ & $\begin{array}{l}0.026 \\
0.045 \\
0.065 \\
0.105 \\
0.127 \\
0.162 \\
0.188 \\
0.223 \\
0.259 \\
0.285 \\
0.318 \\
0.329 \\
0.362 \\
0.373\end{array}$ & $\begin{array}{l}0.025 \\
0.11 \\
0.28 \\
0.41 \\
0.67 \\
0.86 \\
1.245 \\
1.565 \\
1.75 \\
2.01 \\
2.42 \\
2.44 \\
2.49 \\
2.38\end{array}$ & $\begin{array}{c}0 \\
0 \\
0 \\
0 \\
0.14 \\
0.255 \\
0.49 \\
0.825 \\
1.09 \\
1.7 \\
2.21 \\
2.35 \\
3.29 \\
3\end{array}$ & $\begin{array}{l}0.025 \\
0.11 \\
0.28 \\
0.41 \\
0.81 \\
1.115 \\
1.735 \\
2.39 \\
2.84 \\
3.71 \\
4.63 \\
4.79 \\
5.78 \\
5.38\end{array}$ & $\begin{array}{c}0 \\
0 \\
0 \\
0 \\
0 \\
0.06 \\
0.445 \\
0.765 \\
0.95 \\
1.21 \\
1.62 \\
1.64 \\
1.69 \\
1.58\end{array}$ \\
\hline
\end{tabular}


Figure 4: Cumulative Percent Conversion of Previtamin $\mathrm{D}_{3}$ and Lumisterol from $8 \mathrm{AM}$ to $3 \mathrm{PM}$

Presque Isle August 17, 2000

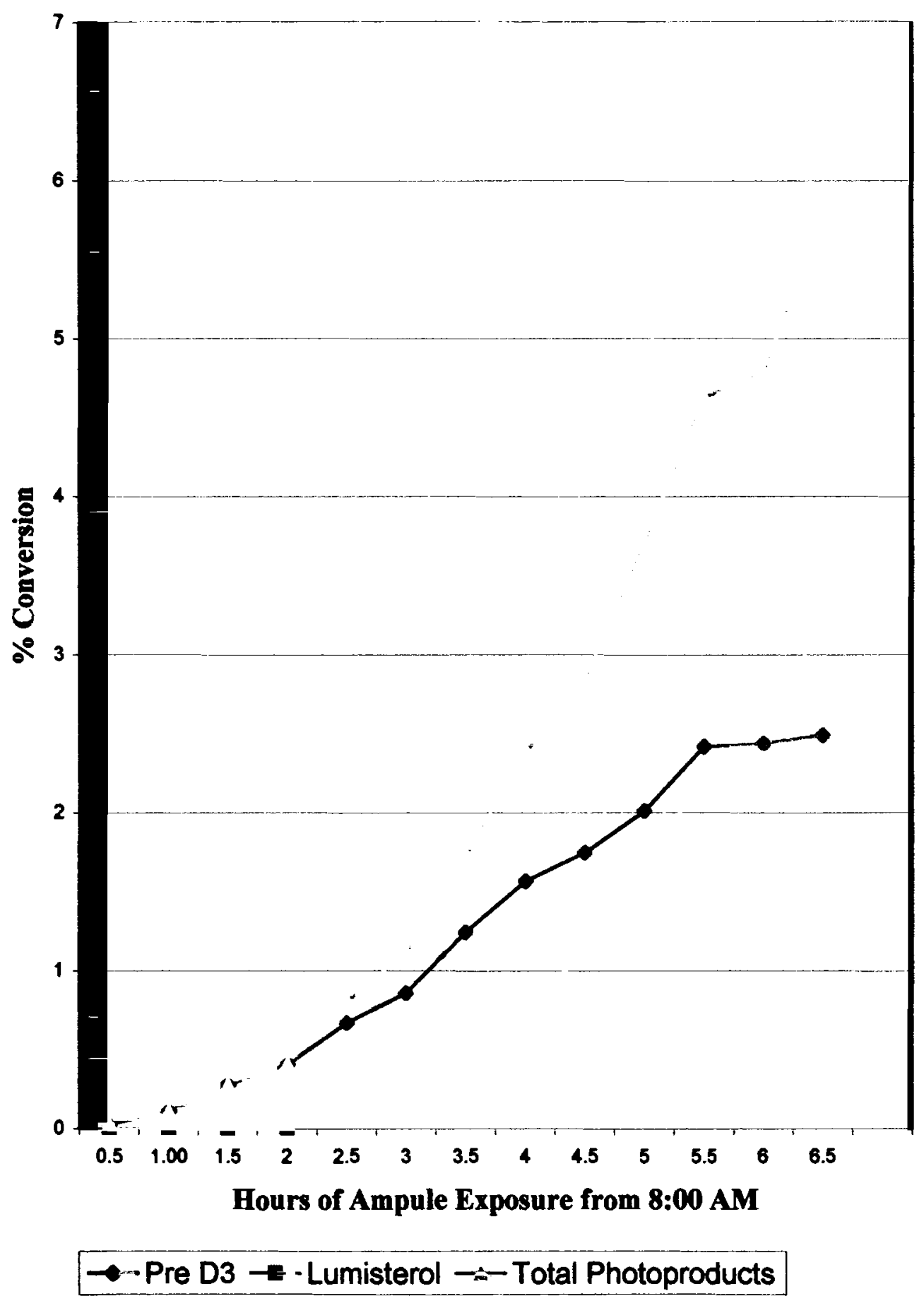


In Orono, the percent pre $\mathrm{D}_{3}$ in the ampules exposed from 12-1 PM in Orono was almost equal to the percent pre $\mathrm{D}_{3}$ in the ampules exposed all day (6 AM-7 PM). There was 12.5 times more lumisterol in the ampules exposed all day than in the ampules exposed from 12-1 PM, see Figure 5 and Table 5.

Figure 5: Comparison of Percent Previtamin $D_{3}$ and Lumisterol Formation in Ampules Exposed One Hour vs. All Day

Orono August 17, 2000

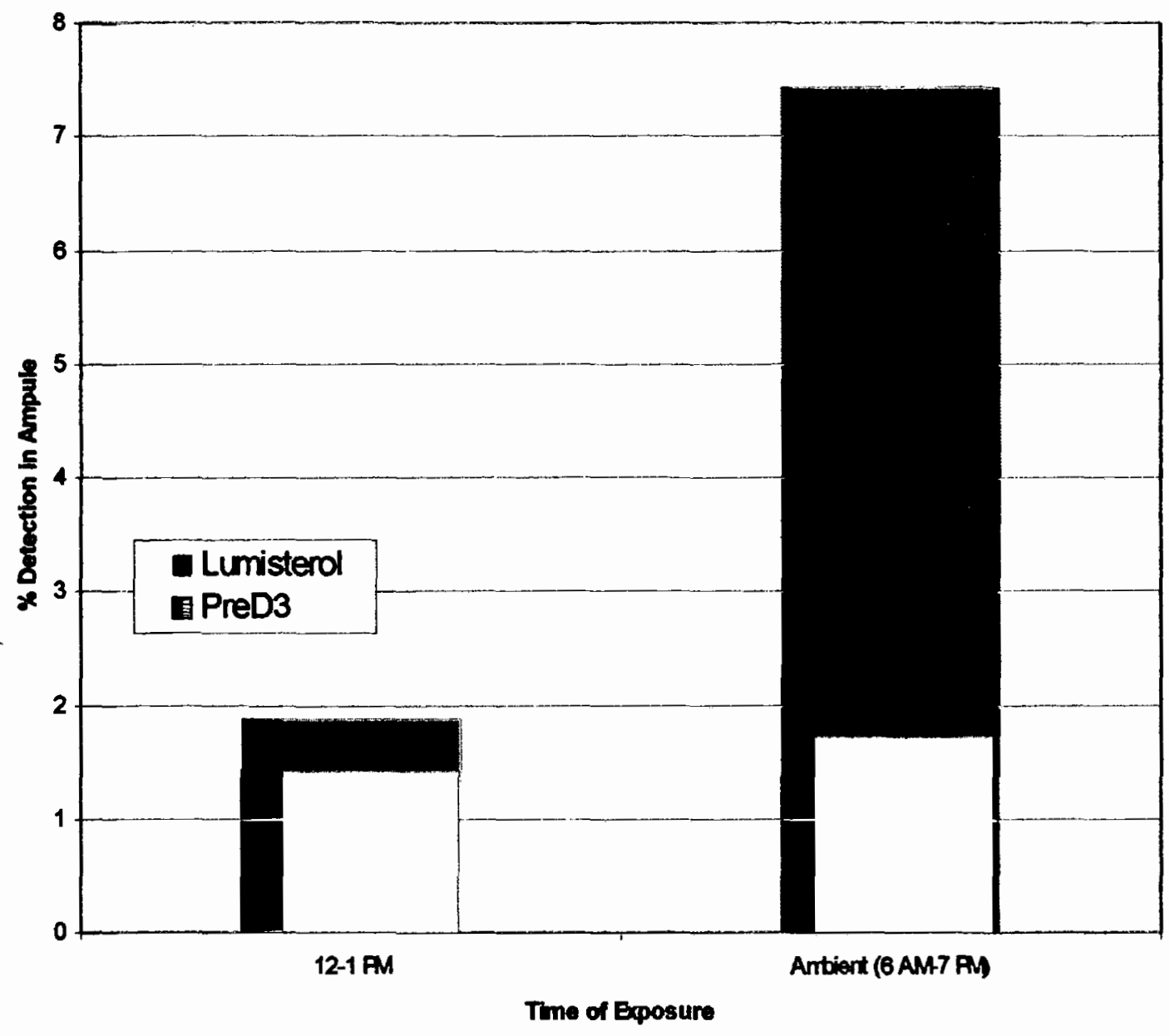


Effect of Time of Day on Previtamin $\mathrm{D}_{3}$ Synthesis

The time of day spent outside had a significant influence on $\mathrm{pre}_{3}$ production. Ampules exposed from 10-11 AM and 2-3 PM had about $30 \%$ less pre $\mathrm{D}_{3}$ production than ampules exposed from 12-1 PM. In ampules exposed from 4-5 PM, there was $71 \%$ less preD $_{3}$ formation (Table 5, Figure 6).

Figure 6: Hourly Production of Previtamin $\mathrm{D}_{3}$

Orono August 17, 2000

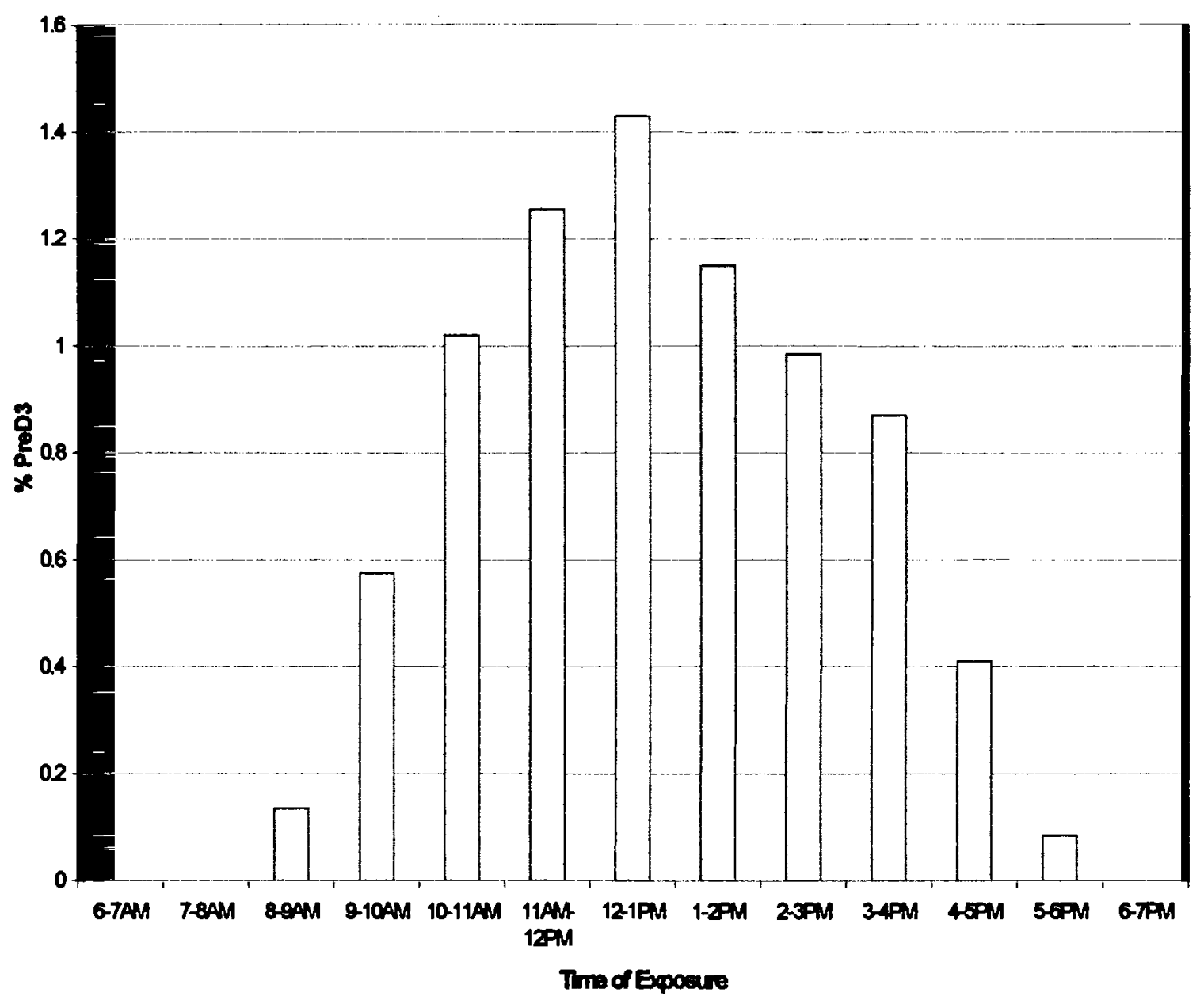


Effect of Season on Previtamin $D_{3}$ Synthesis: August vs. February

On August 17, 2000, skin synthesis of $\mathrm{preD}_{3}$ appeared to begin between 10 and 11 AM (Table 5). During this hour, the average UVB was $0.768(0.710-0.892)$ watts $/ \mathrm{m}^{2}$, the badge reading was 0.106 and the percent pre $_{3}$ formation was 1.02 . On February 22, 2000 , the greatest hourly average of UVB levels occurred between 11 AM and 12 PM. During this hour, the average UVB was $0.807(0.766-0.828)$ watts $/ \mathrm{m}^{2}$, the badges on the horizontal plane had an average reading of 0.066 , and the percent pre $\mathrm{D}_{3}$ formation was 0.34 (Table 7).

Table 7

Comparison of UVB, Badge and Ampule

Data in August vs. February

\begin{tabular}{lll} 
& August 17 & February 22 \\
& (10-11 AM) & (11 AM-12 PM) \\
\hline UVB & 0.768 & 0.807 \\
$\Delta A$ & 0.106 & 0.066 \\
\% PreD & 1.02 & 0.34 \\
\hline
\end{tabular}

Even though there were similar total broadband UVB levels during these hours in February and in August, this did not correspond to equivalent $\mathrm{preD}_{3}$ production or change of absorbance of polysulphone badges. This inconsistency is due to the differences in wavelengths in the solar spectrum in summer vs. winter.

UVB spectral data for two points of time with equivalent broadband UVB levels in February and in August were used to compare the relative strengths of different wavelengths during these times. In Presque Isle, Maine on February 22, 2000 at 11:30 AM, the UVB level was 0.814752 watts $/ \mathrm{m}^{2}$. The solar zenith angle of the sun (SZA) at 
this point was 62.11 degrees. On August 17, 2000 at 10:21 AM, the UVB level also was 0.814752 watts $/ \mathrm{m}^{2}$. The SZA was 43.98 degrees, meaning the sun was more directly overhead than in February. Table 8 shows that the strength of the wavelength at $295 \mathrm{~nm}$ was thirty-three times stronger in August than in February and the $300 \mathrm{~nm}$ wavelength was more than five times stronger in August. The strength of the UVB irradiation was almost equal on the two days at $312 \mathrm{~nm}$. The UVB rays were stronger in February at the longer wavelengths $(313-316 \mathrm{~nm})$.

Table 8

Comparison of Solar Spectrum Between a Point of Time in Winter vs. Summer With Equivalent Broadband UVB (UVB $=0.814725$ watts $/ \mathrm{m}^{2}$ )

\begin{tabular}{|c|c|c|c|}
\hline Wavelength (nm) & $\begin{array}{c}\text { 17-Aug-00 } \\
\text { 10:21 AM } \\
\text { Wavelength } \\
\text { Strength } \\
\text { (Watts/m })\end{array}$ & $\begin{array}{c}\text { 22-Feb-00 } \\
\text { 11:30 AM } \\
\text { Wavelength } \\
\text { Strength } \\
\left.\text { (Watts/m } \text { ( }^{2}\right)\end{array}$ & $\begin{array}{l}\text { Magnitude of } \\
\text { Difference }\end{array}$ \\
\hline 295 & $1.13 E-05$ & $3.43 E-07$ & Aug $33 \times$ stronger \\
\hline 296 & $2.91 E-05$ & $1.35 E-06$ & Aug $22 x$ stronger \\
\hline 297 & $1.00 E-04$ & 7.47E-06 & Aug $13.4 x$ stronger \\
\hline 300 & $6.50 E-04$ & $1.21 E-04$ & Aug $5.37 x$ stronger \\
\hline 306 & $1.31 E-02$ & $7.51 E-03$ & Aug $1.74 x$ stronger \\
\hline 311 & $4.94 E-02$ & 4.60E-02 & Aug $1.07 x$ stronger \\
\hline 312 & $5.56 \mathrm{E}-02$ & 5.72E-02 & $\begin{array}{l}\text { Wavelengths are } \\
\text { almost equal }\end{array}$ \\
\hline $\begin{array}{l}313 \\
316\end{array}$ & $\begin{array}{l}6.38 E-02 \\
7.78 E-02\end{array}$ & $\begin{array}{l}6.70 \mathrm{E}-02 \\
9.63 \mathrm{E}-02\end{array}$ & $\begin{array}{l}\text { Feb } 1.05 \times \text { stronger } \\
\text { Feb } 1.24 \times \text { stronger }\end{array}$ \\
\hline
\end{tabular}

Estimation of Skin Synthesis of Previtamin $\mathrm{D}_{3}$

Skin synthesis of $\operatorname{preD}_{3}$ is not equivalent to the conversion to $\operatorname{preD}_{3}$ in ampules. Skin contains more UVB photon-absorbing substances. It has been found that during the same exposure conditions, $0.8 \%$ of $7-\mathrm{DHC}$ is converted to $\mathrm{preD}_{3}$ in a solution of 7-DHC and ethanol in ampules before $\mathrm{preD}_{3}$ is detected in the skin (58). Thus, subtracting 0.8 from the ampule production of preD $_{3}$ estimates the net amount of pre $\mathrm{D}_{3}$ that would have been formed in the skin. On the study day, Table 5 indicates that by utilizing this 
analysis, $\mathrm{preD}_{3}$ production in the skin would have occurred between the hours of $10 \mathrm{AM}$ and $4 \mathrm{PM}$ in Orono.

The correlation between badge readings and $\mathrm{pre}_{3}$ production in ampules in Orono was 0.98 and in Presque Isle was 0.99 . Thus, both badges and ampules responded to UVB rays similarly (Figure 3 ). On the study day, skin synthesis of $\mathrm{preD}_{3}$ can be estimated to have occurred at badge readings above 0.1 (Tables 5 and 6). Generally, badges worn by the subjects indicate that skin synthesis of $\mathrm{preD}_{3}$ would have occurred with time spent outdoors over 100 corrected minutes (Table 1). Three of the thirteen subjects with badge readings over 0.1 reported less than 100 corrected minutes outdoors. Comparison of Badge Readings in Presque Isle vs. Orono

Because subject minutes outdoors were corrected based on UVB values read from a UVB pyranometer in Presque Isle and most of the subjects were in the Bangor/Orono area, badge readings from badges exposed in Presque Isle and Orono were compared to see if there was a difference in UVB intensity between the two locations. The correlation between badges exposed in Orono and in Presque Isle during the same hours of the day was 0.99 . A paired t-test indicates there is no significant difference between the means of the badge readings (Table 9). This correlation is also demonstrated by plotting the Orono badge readings vs. the Presque Isle badge readings. Figure 7 indicates that the intercept $=0.001$ for this plot. 
Table 9

Comparison of Badges Exposed During the Same Hours in Orono and Presque Isle

\begin{tabular}{ccc}
\hline Time of Day & $\begin{array}{c}\text { Orono Badge } \\
\text { Reading } \\
(\Delta \mathbf{A})\end{array}$ & $\begin{array}{c}\text { Presque Isle } \\
\text { Badge Reading } \\
(\Delta \mathbf{A})\end{array}$ \\
\hline 8 AM-9 AM & 0.032 & 0.045 \\
8 AM-10 AM & 0.113 & 0.105 \\
8 AM-11 AM & 0.185 & 0.162 \\
8 AM-12 PM & 0.235 & 0.223 \\
8 AM-1 PM & 0.317 & 0.285 \\
8 AM-2 PM & 0.321 & 0.329 \\
8 AM-3 PM & 0.355 & 0.376 \\
& & \\
p=0.50 & & \\
r=0.99 & & \\
\hline
\end{tabular}

Figure 7: Plot of Orono Badge Readings vs. Presque Isle Badge Readings Exposed During Same Times of Day

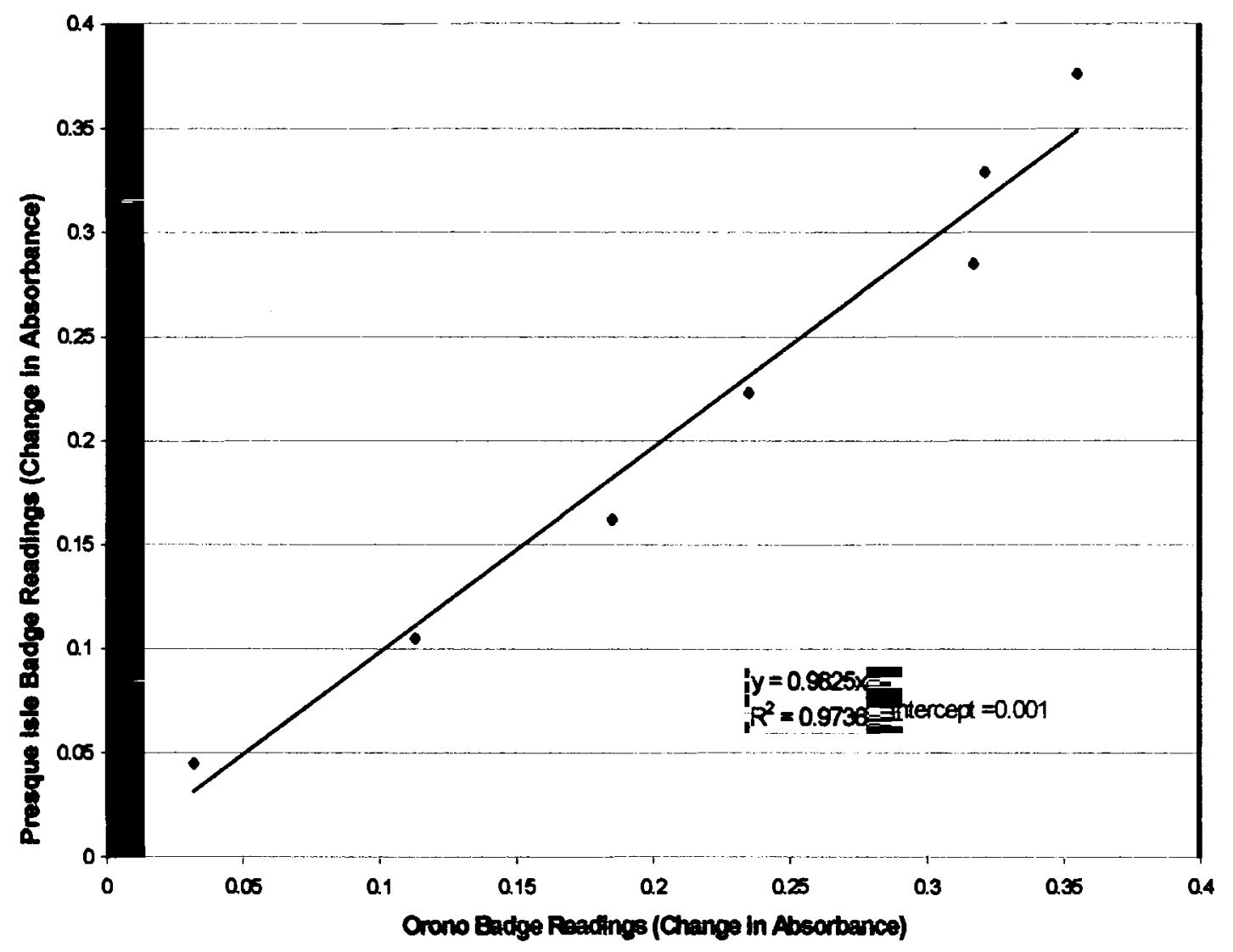




\section{Calibration Equation}

Using cumulative UVB values detected by the pyranometer and the series of badges exposed next to the pyranometer in Presque Isle, a calibration curve was generated where absolute UVB exposure can be determined for other badge readings.

The general form of the calibration curve is $U V B=K\left(9 a^{3}+a^{2}+a\right)$ where $a$ is the change in absorbance and $\mathrm{K}$ is a constant. The calibration obtained from the data in this study is $\mathrm{UVB}=25.74\left(9 \mathrm{a}^{3}+\mathrm{a}^{2}+\mathrm{a}\right) \mathrm{kJ} / \mathrm{m}^{2}$. Table 10 shows the cumulative UVB dose that was associated with different levels of $\mathrm{preD}_{3}$ synthesis during each hour of the day in Orono.

Table 10

Cumulative UVB Dose for Each Hour of the Day in Orono

\begin{tabular}{lcccc}
\hline Time of Day & $\begin{array}{c}\text { Badge } \\
\text { Reading }\end{array}$ & $\begin{array}{c}\text { UVB } \\
\text { Cumulative } \\
\left(\text { KJ/m }^{2}\right)\end{array}$ & $\begin{array}{c}\text { PreD, } \\
(\%)\end{array}$ & $\begin{array}{c}\text { Skin } \\
\text { synthesis } \\
\left(\text { PreD }_{3}-0.8\right)\end{array}$ \\
\hline AMBIENT & 0.401 & 29.40 & 1.73 & 0.93 \\
6-7 AM & 0.008 & 0.21 & 0 & 0 \\
7-8 AM & 0.006 & 0.16 & 0 & 0 \\
8-9 AM & 0.032 & 0.86 & 0.135 & 0 \\
9-10 AM & 0.096 & 2.91 & 0.575 & 0 \\
10-11 AM & 0.106 & 3.29 & 1.02 & 0.22 \\
11 AM-12 PM & 0.141 & 4.79 & 1.255 & 0.455 \\
12-1 PM & 0.176 & 6.59 & 1.43 & 0.63 \\
1-2 PM & 0.141 & 4.79 & 1.15 & 0.35 \\
2-3 PM & 0.12 & 3.86 & 0.985 & 0.185 \\
3-4 PM & 0.123 & 3.99 & 0.87 & 0.07 \\
4-5 PM & 0.07 & 2.01 & 0.41 & 0 \\
5-6 PM & 0.022 & 0.58 & 0.085 & 0 \\
6-7 PM & 0.012 & 0.31 & 0 & 0 \\
\hline
\end{tabular}




\section{DISCUSSION}

\section{Sun-Exposure Questionnaire Validation}

The data on time spent outdoors reported by the subjects was useful in stratifying the girls according to UVB exposure and correlated well with polysulphone badge readings. In fact, correlations between badge readings and minutes spent outdoors, corrected for the strength of the sun ( $r=0.71$ ), were higher than a previously published data on self-report by adolescents of time spent outdoors (44). The reason for the excellent correlation was most likely due to the methodology of the study (24-hour recall reported from activity record) and the comprehensive nature of the questionnaire, which factors in the time of day of sun exposure. Dwyer et al. (44) utilized polysulphone badges to validate two questionnaires of habitual sun exposure with a population of children ages 14-15 years. The best correlation with badge readings occurred when the subjects were asked to keep a diary of activities on the same days that they wore the badges. The correlations between badge readings and self-report from the diaries were in the range of 0.42-0.69. In analysis, Dwyer el al. (44) considered two categories of time of sun exposure, morning and afternoon. The specific time of day was not a factor in analysis.

O'Riordan et al. (59) compared PS badge readings to reported time spent outside by mothers and their young children. The authors relate the poor correlation $(r=0.32$ for mother, $r=0.34$ for child) to using a 4 -day recall-based diary instead of a 24-hour recall format and on the need for better methodologies in estimating sun exposure, such as more information on grades of sun exposure. This current study is the first sun-exposure questionnaire, used in conjunction with vitamin $\mathrm{D}$ research, that takes the varying 
strength of UVB rays into consideration and exemplifies the importance of quantifying the strength of the sun's rays when reporting time spent outdoors. This study also shows that relative to each other, adolescent girls are able to self-report time spent outdoors, particularly the older age group.

\section{Subject Badges vs. Badges Exposed on Horizontal Plane}

The strong correlation between questionnaire results and badge readings demonstrates that the relative minutes outdoors reported by subjects and the objective measures of sun exposure were significantly related. However, the correlations do not indicate the accuracy of the subjects in reporting actual time spent outdoors. A badge reading that corresponds to subject corrected minutes outdoors (from regression line on Figure 1) does not equal the reading from a badge exposed on a horizontal plane for the same number of corrected minutes (Figure 2). For example, 100 corrected minutes corresponds to a subject badge reading of less than 0.1 , yet it corresponds to a badge reading of approximately 0.2 on the horizontal plane. The badges exposed on the horizontal plane cannot be used to check the validity of the subject reported minutes because the badges are utilized in a different fashion. The badges laying on the horizontal flat surface were directly exposed to the sun during the entire length of exposure, whereas the badges worn by the subjects may have been shaded or not in direct contact with the sun during part of the time spent outdoors. Thus, the use of the polysulphone badges in this study shows that the sun-exposure questionnaire is useful as a measure of relative amount of sun exposure. The badges are not useful as an indicator of absolute time spent in the sun in this population of adolescent girls. 
Herlihy et al. (52) utilized polysulphone badges worn by subjects to determine the amount of UVB exposure obtained during different activities, such as gardening or tennis. The researchers also placed "surface" badges on the horizontal plane in the same location where each activity was taking place. Badges worn by the subjects on all anatomical sites had lower readings $(\Delta \mathrm{A})$ than surface badges. For example, the badge worn on the chest by the subject playing golf had a change in absorbance of $30 \%$ of the surface badge reading. Herlihy et al. (52) found that the best correlations between badge readings and subject activity diaries occurred when the badges were worn on the cheek, shoulder or back. However, the researchers also found that the best anatomical site for the badge placement differs with each activity.

The UVB exposure of the polysulphone badges worn by the subjects (sometimes shaded and not directly exposed to the sun) are arguably the same as the actual skin exposure to UVB when subjects are outdoors. An individual may be outdoors without having exposed skin in direct contact with the sun's rays. In both instances, a certain amount of exposure will come from scattered radiation (53). To approximate the badge readings on the horizontal plane, subjects would have to lay directly in the sun. One hour of sun exposure on the study day anytime between 10:00 AM and 4:00 PM would have resulted in physiologically significant skin synthesis of previtamin $\mathrm{D}_{3}$. Subject data from badge readings indicates that one hour was not sufficient to synthesize pre $\mathrm{D}_{3}$. If badges worn by subjects who are changing positions and the angle in which the sun hits the skin can approximate the actual skin exposure to UVB rays, it can be concluded that on a cloudy day in August, it takes more than casual outdoor exposure to produce previtamin $D_{3}$ in the skin. 


\section{Standardizing the Correction Factor}

In analyzing the sun-exposure questionnaire, the hourly strength of UVB rays relative to the hour of peak UVB strength was used to correct the number of minutes spent outdoors. Comparing the average hourly UVB levels between August 17 and August 26, 2000 indicates that two days within a month may have significantly different average hourly UVB levels. The variation in average UVB levels with time for the study day and cloudless day is shown is Table 3 . The shape of the UVB curves for both days is depicted in Appendix B. The plot of the UVB radiation of the study day with variable cloudiness did not follow the bell-shaped curve that is seen on cloudless days, reaching the highest point mid-day and dropping off on either side. Typically in the summer, the time of peak UVB intensity occurs between 12:00 PM and 1:00 PM (60). On August $17^{\text {th }}$, the study day, the peak UVB occurred between 11:00 AM and noon. Another variation from a typical sunny day was that the average UVB levels were greater between 3:00 PM and 4:00 PM than they were between 2:00 PM and 3:00 PM (Table 3). The peak UVB intensity on August $26^{\text {th }}$, the cloudless day, occurred at 12:33 PM and the greatest hourly average UVB occurred between 12:00 and 1:00 PM. Examination of other plots from the UVB pyranometer in Presque Isle shows that this is the norm for a summer day when there is minimal cloud interference.

For research purposes, if the most accurate absolute measure of UVB exposure is to be obtained, it would be optimal to correct minutes based on UVB values for the study day. It would also be necessary to have a UVB pyranometer in the same locale as the study subjects. If the objective is to report relative time in the sun, this study reveals the possibility of standardizing the correction factor, to be used for at least a month. The 
correlation of minutes corrected using UVB data from August 26, 2000 and subject badge readings was essentially the same as when the minutes were corrected on the study day ( $r=72$ vs. $r=.71$ ), even though each hour's fractional equivalent was different. Most importantly, there was a better correlation between minutes spent outdoors and badge readings using either correction factor (UVB from study day or from cloudless day) than from using total daily minutes in the sun, illustrating the importance of quantifying the strength of UVB rays during sun exposure.

\section{Factors Affecting Previtamin $D_{3}$ Synthesis}

\section{Time of Day and Length of Sun Exposure}

This study confirmed the connection between time of day spent outside and the potential for previtamin $\mathrm{D}_{3}$ production in the skin. The hourly percent pre $\mathrm{D}_{3}$ formation in ampules in Orono corresponded to a typical UVB bell-shaped curve (Figures 3 and 6). The hour during the day with the greatest $\mathrm{preD}_{3}$ and lumisterol formation occurred between 12:00-1:00 PM, the same time as the peak badge reading, and usually the time of peak UVB intensity in the summer. At each hour earlier or later than 12-1 PM, there was less pre $\mathrm{D}_{3}$ detected in the ampules.

This study also confirmed that continued UVB exposure leads to continued conversion of $\mathrm{preD}_{3}$ to lumisterol. Ampules exposed for an hour in the middle of the day in Orono (12:00-1:00 PM) contained a similar amount of $\mathrm{preD}_{3}$ as those exposed all day (6 AM-7 PM), although ampules exposed all day contained more total photoproducts as lumisterol (Figure 5). Once $\mathrm{preD}_{3}$ is formed from 7-DHC, it also absorbs UVB photons to form either lumisterol or tachysterol (25). If the UVB rays are sufficiently strong, preD $_{3}$ synthesis will plateau around $15 \%$ of the original $7-\mathrm{DHC}$ present in the skin or in 
ampules, regardless of skin color or UVB intensity (26). The percent lumisterol will continue to increase with exposure (26). Maximum pre $\mathrm{D}_{3}$ production in Caucasian skin samples was reached after 15 to 30 minutes under simulated equatorial sunlight (26). With increased latitude and reduced UVB intensity, longer exposure time is needed to maximize pre $\mathrm{D}_{3}$ production in the skin. Double the exposure time was required to maximize pre $\mathrm{D}_{3}$ production in skin samples exposed to sunlight strength simulating midday sun in June in Boston (26). The UVB irradiation in Maine on the study day was not strong enough for the maximum conversion of 7-DHC to $\mathrm{preD}_{3}$ in the ampules.

During the cumulative exposure of ampules in Presque Isle, the percent preD $\mathrm{D}_{3}$ and lumisterol continued to increase with time until the rate of conversion to lumisterol overtook the rate of pre $\mathrm{D}_{3}$ production after about five and one-half hours of exposure. It is expected that the percent pre $\mathrm{D}_{3}$ detected in the ampules in Presque Isle would begin to decline with continued exposure, as the percent lumisterol would continue to rise.

Further evidence for this phenomenon is the fact that the ampules exposed from $6 \mathrm{AM}$ to $7 \mathrm{PM}$ in Orono had $1.73 \%$ preD $_{3}$ and those in Presque Isle exposed for fewer hours, from $8 \mathrm{AM}-2: 30 \mathrm{PM}$, contained $2.49 \% \mathrm{preD}_{3}$. The ampules with all day exposure in Orono most likely contained more pre $\mathrm{D}_{3}$ at $3 \mathrm{PM}$ than at $7 \mathrm{PM}$.

Weather

The pre $\mathrm{D}_{3}$ production in the ampules was lower than expected on this August day. In 1992, Rosen et al. (7) utilized a pre $\mathrm{D}_{3}$ in ethanol model on a sunny May day in Maine and detected $2.1 \pm 0.8 \%$ preD $_{3}$ in ampules exposed from 12-1 PM. In July 1992 in Boston, $3.27 \%$ conversion of 7-DHC to preD $\mathrm{D}_{3}$ occurred between $12-1 \mathrm{PM}(32)$. On an August day in Boston, $6 \%$ pre $\mathrm{D}_{3}$ was detected in ampules after exposure from $12-1 \mathrm{PM}$ 
(58). The peak pre $\mathrm{D}_{3}$ conversion in Maine on this August day was $1.43 \%$, much less than occurred in Boston. Including the lumisterol production, the total photoproducts produced in Orono between $12-1$ PM were only $1.89 \%$ of original 7-DHC. The $2.5^{\circ}$ difference in latitude between Boston and Bangor is probably one factor in the difference in pre $\mathrm{D}_{3}$ production. The biggest factor accounting for the smaller percentage of pre $_{3}$ formed in Maine is probably that the study was conducted on a cloudy day. A greater percentage of pre $\mathrm{D}_{3}$ conversion could be expected on a sunny August day. Clouds can reduce the ultraviolet rays from the sun by $50 \%$ or more (60). The average UVB was lower on the study day than on the sunny day in August for each hour until 6 PM. For example, between 2-3 PM, the UVB level on August 26 was more than double that on August 17 (Table 3). As well as time of day spent outside, overall time spent outside, season, and latitude, it is evident that the weather also has a dramatic effect on the potential of $\mathrm{preD}_{3}$ production in the skin.

\section{Season-UVB Wavelength}

Even though the average UVB during an hour in February $\left(0.807\right.$ watts $\left./ \mathrm{m}^{2}\right)$ was marginally greater than the UVB level during an hour on the August study day (0.768 watts $/ \mathrm{m}^{2}$ ), the percent pre $\mathrm{D}_{3}$ production was markedly greater during the August hour than in February ( $1.20 \%$ vs. $0.34 \%$ ). Comparing the spectral data of two points of time with the same UVB level on February 22, 2000 and August 17, 2000 revealed that the shorter wavelengths, those that are most instrumental in producing $\operatorname{pre}_{3}$, were considerably stronger in August than they were in February (Table 8). The strength of the wavelength at $296 \mathrm{~nm}$ was 22 times stronger in August than in February. This data shows that in the winter, as solar irradiation must travel further distances through the 
atmosphere because of the increased solar zenith angle of the sun, the wavelengths at the lower end of the UVB spectrum are selectively filtered out more than the wavelengths at the higher end of the spectrum. Webb et al. (31) monitored the intensities of different UVB wavelengths $(296,300,306$ and $316 \mathrm{~nm})$ during a year. The wavelength of $296 \mathrm{~nm}$ was not detected by a spectrophotometer in the winter in Boston (and pre $\mathrm{D}_{3}$ was not produced in the skin). The wavelength of $296 \mathrm{~nm}$ was first detected by the spectrophotometer in March. March was also the month where pre $\mathrm{D}_{3}$ was first detected in the skin. Detection of $296 \mathrm{~nm}$ ceased in October. The authors conclude that preD 3 production in the fall months primarily occurs from the longer wavelengths between 300 $315 \mathrm{~nm}(31)$. 


\section{CONCLUSIONS}

The main outcome of this study is the determination that relative to each other, adolescent girls are able to self-report time spent outdoors. The strong correlation between self-reported sun exposure and the objective measure of sun exposure illustrates the other main conclusion that the time of day spent outside is a crucial component of a sun-exposure questionnaire. This is the first sun-exposure questionnaire, used in conjunction with vitamin $\mathrm{D}$ research, which incorporates a method to standardize minutes in the sun based on the strength of UVB rays, a factor that directly affects the amount of previtamin $D_{3}$ synthesis in the skin.

Results of this study bring attention to the fact that even during the summer, when UVB rays are strongest, weather and time of day substantially affect vitamin D synthesis in the skin. Depending on the time of day of usual sun exposure and cloud cover, it may take more than casual outdoor exposure to produce a physiologically significant amount of vitamin $D$ in the summer. No vitamin $D$ production occurs in the skin in winter in Maine and other northern climates. Because of the inconsistent supply of vitamin $D$ from the sun in northern climates, adequate dietary vitamin $D$ intake yearround is important. 


\section{APPLICATIONS AND RECOMMENDATIONS}

This sun-exposure questionnaire is comprehensive in covering many of the factors that affect skin synthesis of vitamin D. Season, latitude and time of day of sun exposure are factored into analysis by utilizing UVB data to establish a correction factor for each hour of the day. Clothing worn and sunscreen use encompass body surface area exposed. Once a correction factor is set, this sun-exposure questionnaire is easy to administer and analyze, as this questionnaire is simply a 24-hour report of activity using the same rationale as 24 -hour recall of diet and physical activity methodologies.

If the objective is to stratify subject sun exposure relative to one another, this study shows it is reasonable to utilize UVB data on a typical sunny day to standardize hourly correction factors. Standardizing the correction factor would be particularly useful if the UVB pyranometer is not in the same location as the subjects, because cloud cover over the two locations may differ. There are 30 USDA UVB Monitoring Sites in the United States and Canada, and daily UVB data is readily available to download from the Internet.

The sun-exposure questionnaire was originally devised to assess general sun exposure over a season ( 3 months). This format required that subjects describe outdoor activities on a typical day and included a section to describe atypical days, when there may have been more or less outdoor activity than usual (See Appendix H). This questionnaire may be better suited to assess sun exposure patterns of adults and the elderly, as they are more apt to be able to report typical behavior and tend to follow stable work or activity schedules. This original questionnaire may be useful as a selfassessment or screening tool. 
The revised sun-exposure questionnaire is currently being used as four nonconsecutive 24-hour recalls of daily activities and time spent outdoors during the summer months. There is no need to quantify sun exposure during the winter months in Maine, from at least November to February and probably most of October and March (31). A previous study conducted by this researcher verified that there was no significant pre $\mathrm{D}_{3}$ synthesis in the skin on a sunny day in February in Maine (unpublished data). With a standardized correction factor, this sun-exposure questionnaire will be practical for use in a variety of research applications or with dietary data as a screening tool for sub-optimal vitamin D status or osteoporosis risk.

This research provides a comprehensive study of one day. Comparing absolute measures of hourly and cumulative PS badges readings, $\mathrm{pre}_{3}$ production in ampules and UVB strength contributes to further understanding the relationship between UVB exposure and vitamin D synthesis in the skin. Further research utilizing 7- DHC ampules during different seasons and weather conditions is necessary to fully understand the Maine climate in reference to vitamin D synthesis. Data collected on a sunny day during peak summer UVB levels in June or July would determine the potential for the greatest amount of pre $\mathrm{D}_{3}$ production possible in Maine (with the present ozone concentration). Daily analysis of ampules exposed during the fall and spring would clarify the point of time when there is minimal or no synthesis of pre $\mathrm{D}_{3}$ in the skin. Exposing ampules at different altitudes and surface conditions (snow, water) in Maine would further add to the knowledge. 


\section{REFERENCES}

1. Standing Committee on the Scientific Evaluation of Dietary Reference Intakes, Food and Nutrition Board, Institute of Medicine. Dietary Reference Intakes for Calcium, Phosphorus, Magnesium, Vitamin D, and Fluoride. Washington, D.C.: National Academy Press; 1997.

2. Holick MF. McCollum Award Lecture, 1994: Vitamin D-new horizons for the $21^{\text {st }}$ century. Am J Clin Nutr. 1994;60:619-630.

3. Holick MF, MacLaughlin JA, Clark MB, Holick SA, Potts JT. Photosynthesis of previtamin $\mathrm{D}_{3}$ in human skin and the physiologic consequences. Science. 1980;210:203205.

4. Dawson-Hughes B, Harris SS, Dallal GE. Plasma calcidiol, season, and serum parathyroid hormone concentrations in healthy elderly men and women. Am JClin Nutr. 1997;65:67-71.

5. Jacques PF, Felson DT, Tucker KL, Mahnken B, Wilson PWF, Rosenberg IH, Rush D. Plasma 25-hydroxyvitamin $\mathrm{D}$ and its determinants in an elderly population sample. Am J Clin Nutr. 1997;66:929-936.

6. Salamone LM, Dallal GE, Zantos D, Makrauer F, Dawson-Hughes B. Contributions of vitamin D intake and seasonal sunlight exposure to plasma 25-hydroxyvitamin D concentrations in elderly women. Am J Clin Nutr. 1993;58:80-86.

7. Rosen CJ, Morrison A, Zhou H, Storm D, Hunter SJ, Musgrave K, Chen T, Wei W, Holik MF. Elderly women in northern New England exhibit seasonal changes in bone mineral density and calciotropic hormones. Bone \& Mineral. 1994;25:83-92.

8. Webb AR, Pilbeam C, Hanafin N, Holick MF. An evaluation of the relative contributions of exposure to sunlight and of diet to the circulating concentrations of 25hydroxyvitamin D in an elderly nursing home population in Boston. Am J Clin Nutr. 1990;51:1075-1081.

9. Need AG, Morris HA, Horowitz M, Christopher Nordin, BE. Effects of skin thickness, age, body fat, and sunlight on serum 25 -hydroxyvitamin D. Am J Clin Nutr. 1993;58:882-885.

10. Davies PSW, Bates CJ, Cole TJ, Prentice A, Clarke PC. Vitamin D: seasonal and regional differences in preschool children in Great Britain. Eur J Clin Nutr. 1999;195199.

11. Guillemant J, Cabrol S, Allemandou A, Peres G, Guillemant S. Vitamin Ddependent seasonal variation of PTH in growing male adolescents. Bone. 1995;17:513516. 
12. Docio S, Riancho JA, Perez A, Olmos JM, Amado JA, Gonzalez-Macias J. Seasonal deficiency of vitamin $D$ in children: a potential target for osteoporosis-preventing strategies? J Bone Miner Res. 1998;13:544-548.

13. Oliveri B, Wittich A, Mautalen C, Kizlansky A, Chaperon A. Vitamin D deficiency does not influence peak bone mass in Ushuaia. In: Burchkardt P, Dawson-Hughes B, Heaney R, eds. Nutritional Aspects of Osteoporosis. Norwell, MA: Serono Symposia USA;1998:244-248.

14. Poskitt EME, Cole TJ, Lawson DEM. Diet, sunlight, and 25-hydroxyvitamin D in healthy children and adults. British Med J. 1979;1:221-223.

15. Guillemant J, Guillemant S. Acute PTH response to oral calcium load and seasonal variation of vitamin D status in healthy young adult subjects. Eur J Clin Nutr. 1996;50: 469-72.

16. Zittermann A, Scheld $K$, Stehle $P$. Seasonal variations in vitamin $D$ status and calcium absorption do not influence bone turnover in young women. Eur J Clin Nutr. 1998;52:501-506.

17. Holick MF. Vitamin $D_{3}$ and sunlight: An intimate beneficial relationship. In: Holick MF, Kligman AM, eds. Biological Effects of Light. Berlin: Walter de Gruyter; 1992:1133.

18. Combs, GF. The Vitamins: Fundamental Aspects in Nutrition and Health. San Diego, CA: Academic Press;1998:156-177.

19. Lips $P$, van Ginkel FC, Jongen MJM, Rubertus F, van der Vijgh WJF, Netelenbos JC. Determinants of vitamin D status in patients with hip fracture and in elderly control subjects. Am J Clin Nutr. 1987;46:1005-1010.

20. Holick MF. Environmental factors that influence the cutaneous production of vitamin D. Am J Clin Nutr. 1995;61:638S-645S.

21. Holick MF, Shao Q, Liu WW, Chen TC. The vitamin D content of fortified milk and infant formula. New Engl J Med. 1992;326:1178-1181.

22. DeLuca HD. Vitamin D: 1993. Nutrition Today. November/December 1993;6-11.

23. Holick MF. The use and interpretation of assays for vitamin $\mathrm{D}$ and its metabolites. $J$ Nutr. 1990;120:1464-1469.

24. Holick MF. Vitamin $D$ in health and prevention of metabolic bone disease. In: Rosen CJ, ed. Osteoporosis: Diagnostic and Therapeutic Principles. Totowa, NJ: Humana Press; 1996:29-43. 
25. Holick MF. The cutaneous photosynthesis of previtamin D3: a unique photoendocrine system. Invest Dermatol. 1981;76:51-58.

26. Holick MF, MacLaughlin JA, Doppelt SH. Regulation of cutaneous previtamin $\mathrm{D}_{3}$ photosynthesis in man: skin pigment is not an essential regulator. Science. 1981;211:590-593.

27. Webb AR, DeCosta BR, Holick MF. Sunlight regulates the cutaneous production of vitamin $\mathrm{D}_{3}$ by causing its photodegradation. J Clin Endocrinol Metab. 1989;68:882-887.

28. MacLaughlin J, Holick MF. Aging decreases the capacity of human skin to produce vitamin $\mathrm{D}_{3}$. J Clin Invest 1985;76:1536-1538.

29. Lu Z, Chen TC, Holick MF. Influence of season and time of day on the synthesis of vitamin $\mathrm{D}_{3}$. In: Holick MF, Kligman AM, eds. Biologic Effects of Light. Berlin: Walter de Gruyter;1992: 53-56.

30. Gibson JH. UVB Radiation: Definition and Characteristics

Available at: http://www.uvb.nrel.colostate.edu/uvb/uvb.climate_network.html. Accessed October 1, 1999.

31. Webb AR, Kline L, Holick MF. Influence of season and latitude on the cutaneous synthesis of Vitamin $\mathrm{D}_{3}$ : exposure to winter sunlight in Boston and Edmonton will not promote vitamin $\mathrm{D}_{3}$ synthesis in human skin. J Clin Endocrinol Metab. 1988;67:373378.

32. Lu Z, Chen TC, Kline L, Markestad T, Pettifor J, Ladizesky M, Mautalen C, Holick MF. Photosynthesis of previtamin $\mathrm{D}_{3}$ in cities around the world. In: Holick MF, Kligman AM, eds. Biological Effects of Light. Berlin: Walter de Gruyter;1992: 48-52.

33. MacLaughlin JA, Anderson RR, Holick MF. Spectral character of sunlight modulates photosynthesis of previtamin $D_{3}$ and its isomers in human skin. Science. 1982;216:1001.

34. UV Index: Diurnal Variability. Available at:

http://www.cpc.ncep.noaa.gov/products/stratophere/uv_index/uv_diurnal.html. Accessed November 17, 1999.

35. Chesney RW, Rosen JF, Hamstra AJ, Smith C, Mahaffey K, DeLuca HF. Absence of seasonal variation in serum concentrations of 1,25-dihydroxyvitamin $D$ despite a rise in 25-hydroxyvitamin D in summer. J Clin Endocrinol Metab. 1981;53:139-142.

36. Krall EA, Sahyoun N, Tannenbaum S, Dallal GE, Dawson-Hughes B. Effect of vitamin $D$ intake on seasonal variations in parathyroid hormone secretion in postmenopausal women. NEngl J Med. 1989; 321:1777-1783. 
37. Kinyam HK, Gallagher JC, Rafferty KA, Balhorn KE. Dietary calcium and vitamin $D$ intake in elderly women: effect on serum parathyroid hormone and vitamin D metabolites. Am J Clin Nutr. 1998;67:342-348.

38. Dawson-Hughes B, Harris SS, Krall EA, Dallal GE. Effect of calcium and vitamin D supplementation on bone density in men and women 65 years of age or older. $N \mathrm{Engl}$ JMed. 1997; 337:670-76.

39. Woitge HW, Scheidt-Nave C, Kissling C, Leidig-Bruckner G, Meyer K, Grauer A, Scharla SH, Ziegler R, Seibel MJ. Seasonal variation of biochemical indexes of bone turnover: results of a population-based study. JClin Endocrinol Metab. 1998;83:68-75.

40. Jones $G$, Dwyer $T$. Bone mass in prepubertal children: gender differences and the role of physical activity and sunlight exposure. J Clin Endocrinol Metab. 1998;83:42744279.

41. Malvy DJM, Guinot C, Preziosi P, Galan P, Chapuy MC, Maamer M, Arnaud S, Meunier PJ, Hercberg S, Tschachler E. Relationship between vitamin D status and skin phototype in general adult population. Photochem Photobiol. 2000;71:466-469.

42. Jones G, Blizzard CL, Riley MD, Parameswaran V, Greenaway TM, Dwyer T. Vitamin D levels in prepubertal children in Southern Tasmania: prevalence and determinants. Eur J Clin Nutr. $1999 ; 52: 824-829$.

43. Sowers MFR, Wallace RB, Hollis BW, Lemke JH. Parameters related to 25-OH-D levels in a population-based study of women. Am J Clin Nutr. 1986;43:621-628.

44. Dwyer T, Blizzard L, Gies PH, Ashbolt R, Roy C. Assessment of habitual sun exposure in adolescents via questionnaire - a comparison with objective measurement using polysulphone badges. Melanoma Research. 1996;6:231-239.

45. Sallis JF, Buono MJ, Roby JJ, Micale FG, Nelson JA. Seven-day recall and other physical activity self-reports in children and adolescents. Med Sci Sports Exerc. 1993;25:99-108.

46. Sallis JF, Strikmiller PK, Harsha DW, Feldman HA, Ehlinger S, Stone EJ, Williston $\mathrm{J}$, Woods S. Validation of interview- and self-administered physical activity checklists for fifth grade students. Med Sci Sports Exerc. 1996;28:840-851.

47. Going SB, Levin S, Harrell J, Stewart S, Kushi L, Cornell CE, Hunsberger S, Corbin $\mathrm{C}$, Sallis J. Physical activity assessment in American Indian schoolchildren in the Pathways study. Am J Clin Nutr. 1999;69(suppl):788S-795S.

48. Simons-Morton BG, Taylor WC, Huang IW. Validation of the physical activity interview and Caltrac with preadolescent children. Res $Q$ Exerc Sport. 1994;65:84-88. 
49. Slemenda CW, Miller JZ, Hui SL, Reister TK, Johnston Jr CC. Role of physical activity in the development of skeletal mass in children. J Bone Miner Res. 1991;6:12271233.

50. Matsuoka LY, Wortsman J, Dannenberg MJ, Hollis BW, Zhiren LU, Holick MF. Clothing prevents ultraviolet-B radiation-dependent photosynthesis of Vitamin D3. $J$ Clin Endocrinol Metab. 1992;75:1099-1103.

51. Matsuoka LY, Ide L, Wortsman J, MacLaughlin JA, Holick MF. Sunscreens suppress cutaneous vitamin D3 synthesis. JClin Endocrinol Metab. 1987;64:1165-1168.

52. Herlihy E, Gies PH, Roy CR, Jones M. Personal dosimetry of solar UV radiation for different outdoor activities. Photochem. Photobiol. 1994; 60: 288-94.

53. Airey DK, Wong FCF, Fleming RA, Meldrum LR. An estimate of the total UV-B exposure for outdoor workers during a south-east Queensland summer. Health Phys. 1997;72:544-549.

54. Duncan DD, Schneider W, West KJ, Kirkpatrick SJ, West SK and the Salisbury Eye Evaluation Team. The development of personal dosimeters for use in the visible and ultraviolet wavelength regions. Photochem Photobiol. 1995; 62: 94-100.

55. Davis A, Deane GHW, Diffey BL. Possible dosimeter for ultraviolet radiation. Nature. 1976;261:169-170.

56. Parisi AV, Meldrum LR, Kimlin MG. Polysulphone film thickness and its effects in ultraviolet radiation dosimetry. Available at: http://www.photobiologv.com/UVR98/parisi_ Accessed November 1, 1999.

57. Davis A, Diffey BL, Tate TK. A personal dosimeter for biologically effective solar UV-B radiation. Photochem Photobiol. 1981;34:283-286.

58. Chen TC. Photobiology of vitamin D. In: Holick MF, ed. Vitamin D: Physiology, Molecular Biology, and Clinical Applications. Totowa, NJ: Humana Press;1999:17-37.

59. O'Riordan DL, Stanton WR, Eyeson-Alnnan M, Gies P, Roy C. Correlations between reported and measured ultraviolet radiation exposure of mothers and young children. Photochem Photobiol. 2000;71:60-64.

60. United States Environmental Protection Agency. The experimental ultraviolet index factsheet: explaining the index to the public. Available at htpp://www.noas.gov/uvb/fctsh.html Accessed November 17, 1999. 
APPENDIX A

Previtamin $D_{3}$ Synthesis During a Summer and Fall Day 
Figure A.1: Previtamin $\mathrm{D}_{3}$ Synthesis During a Summer and Fall Day In Boston, MA

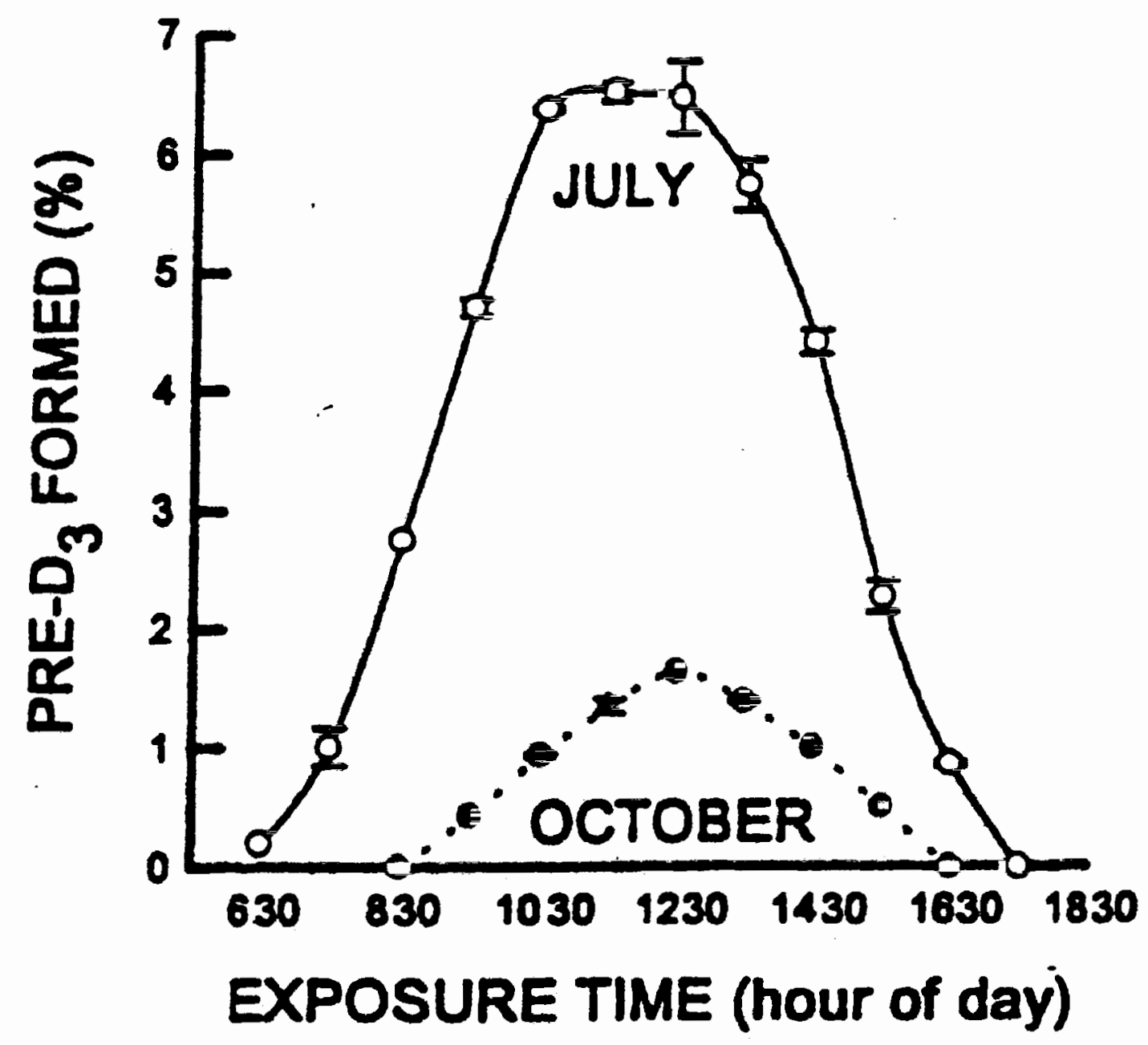

Photosynthesis of precholecalciferol (previtamin $D_{3}$ ) at various times on cloudless days in Boston in October ( $(0)$ and July (O).

Reprinted with permission from:

$\mathrm{Lu} \mathrm{Z,} \mathrm{Chen} \mathrm{TC,} \mathrm{Holick} \mathrm{MF.} \mathrm{Influence} \mathrm{of} \mathrm{season} \mathrm{and} \mathrm{time} \mathrm{of} \mathrm{day} \mathrm{on} \mathrm{the} \mathrm{synthesis} \mathrm{of}$ vitamin $\mathrm{D}_{3}$. In: Holick MF, Kligman AM, eds. Biological Effects of Light. Berlin: Walter de Gruyter;1992: 57-61. 


\section{APPENDIX B}

Plot of UVB Radiation on a Sunny and Cloudy August Day in Maine 
Figure B.1: UVB Plot of Sunny Day in Maine

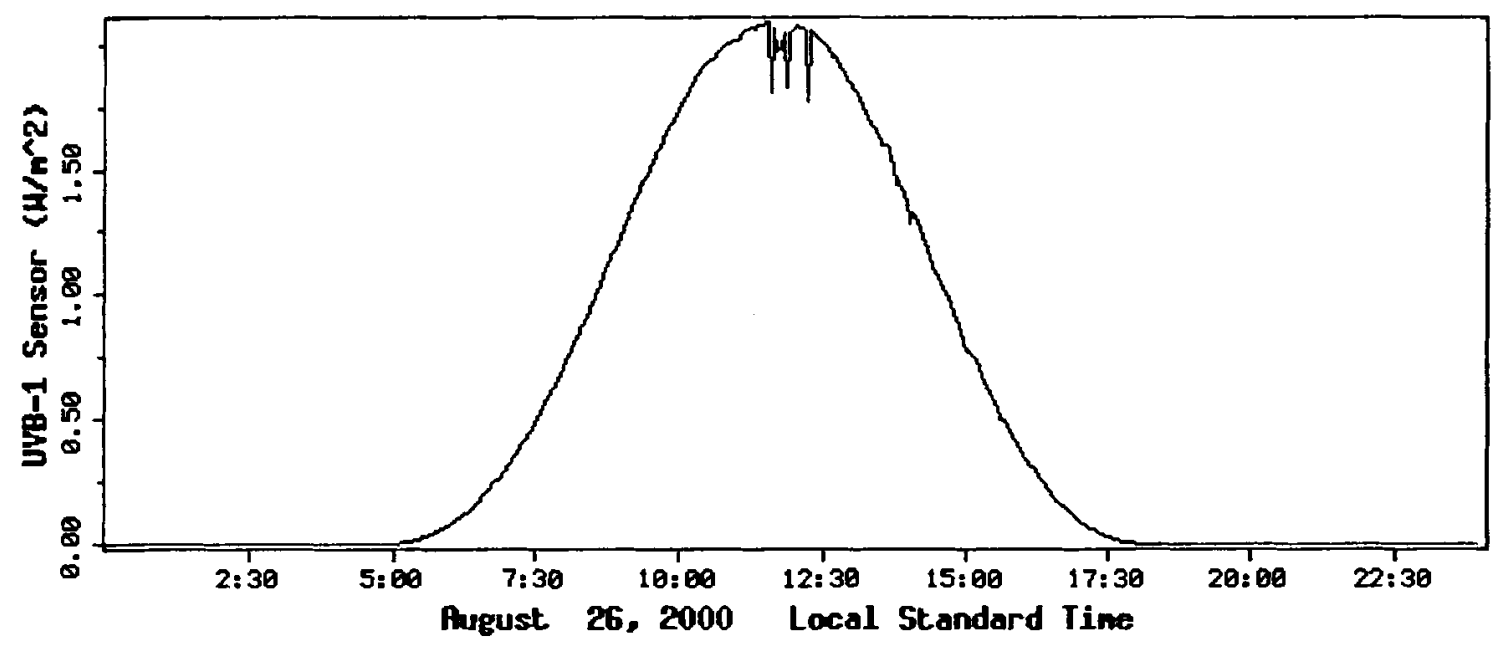

Figure B.2: UVB Plot of Cloudy Day in Maine

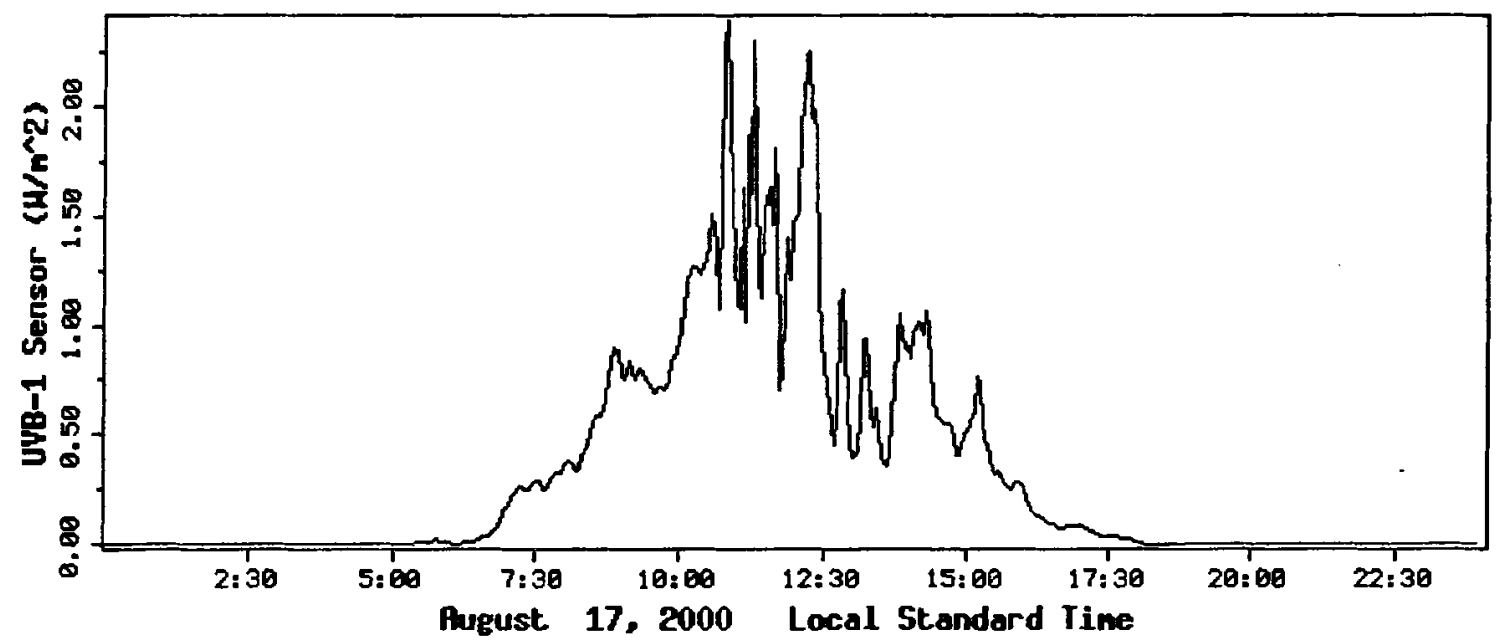

Plots from the USDA UVB Radiation Monitoring Program at Colorado State University National Resource Ecology Laboratory via the World Wide Web at http://uvb.nrel.colostate.edu/UVB_climate_network.html. 
APPENDIX C

Consent and Assent Forms 
Project Title: Validation of a sun-exposure questionnaire for adolescent girls.

I am being asked to give permission for my daughter to participate in the following research study: Validation of a sun-exposure questionnaire for adolescent girls. Jennifer Cobb, a graduate student in Food Science and Human Nutrition at the University of Maine, will conduct this project under the supervision of Susan Sullivan, Assistant Professor.

My daughter is being asked to participate in this study because she is between the ages of 9 and 15 years old. This study is being conducted in order to pre-test the questionnaire for use in a different study of bone mineralization rates of adolescent girls in Maine. My daughter will be asked to wear a small polysulphone badge on her shirt or coat for one day in August. Polysulphone is a type of film that goes through changes when it absorbs rays from the sun. It is possible to measure the amount of sunlight the film is exposed to. The badge will be applied in the morning and removed at night. The polysulphone badge poses no risk and will not change her activity in any way. My daughter will also be asked to keep an activity record during this day. Researchers at the University of Maine will call my daughter the next day to discuss her activity record. My daughter will be asked to report how much time she spent doing each activity the previous day and whether she was inside or outdoors. The phone call will take about 15 minutes.

The study described above involves no risks greater than that of everyday living.

My daughter will receive no direct benefit from participation in the study. The family will receive a $\$ 5.00$ payment and my daughter will receive a small gift. Jennifer Cobb or Susan Sullivan, Jennifer's faculty sponsor, will be available to address any concerns I may have about this project. If the study design or use of information is to be changed, I will be so informed and my consent reobtained.

Participation is voluntary. My daughter has the right to refuse to participate in, or to withdraw from, this research at any time without loss of benefits. She may also skip any questions she does not wish to answer.

Names will be kept confidential. The results of all testing will be recorded on special forms. These forms will have no name on them, but will use a code number to protect my daughter's privacy. All records will be kept in a locked office and my daughter's name will not be used in any publication describing this research. At the completion of the study, all data will be stored in a locked file in Susan Sullivan's office.

I agree to have my daughter participate in this project. 
Project Title: Validation of a sun-exposure questionnaire for adolescent girls.

Jennifer Cobb, a graduate student in Food Science and Human Nutrition at the University of Maine, has asked me to participate in this study because I am a girl between the ages of 9 and 15 years old. I will be asked to wear a small badge for one day, either attached to my shirt, bathing suit or coat. I understand that it needs to be on the outside of any clothes so that the sun can shine on it. This badge will record the amount of sunlight that hits it during the day. I will wear the badge all day and remove it before I go to bed at night. I will keep an activity record on the day that I wear the badge. On this record, I will write down everything I do during the day (all activities and amount of time spent doing each activity).

The next day, a researcher from the University of Maine will call me and ask questions about my activities when I wore the badge. There are no right or wrong answers to the questions. I can skip questions if I do not want to answer them. The researchers will not tell anyone my name or my test results or my answers to the questions. All of my results will use a code number instead of my name. These results will be kept in a locked office.

I will be free to quit the study any time I want. I have had time to think about it and want to be a subject in this research study.

Discussed with subject. Assent received on

$$
\text { date }
$$




\section{APPENDLX D}

Badge Instruction Sheet 


\section{The Sunshine Badge Study}

Instructions for wearing the badge:

- Keep the badge in the film container until the day of the study.

- In the morning, pin the badge to the front upper left-hand corner of your shirt. The badge should stay on your shirt ALL DAY and must not be covered by any clothing. It is OK to change clothes or even to wear a bathing suit. Just remember to pin the badge to the clothes that you are wearing. If you put on a jacket, pin the badge on the jacket. Wear the badge at all times, inside and outdoors, for one day.

- Right before you go to bed, put the badge back into the film container. The badge must not be exposed to sunlight after this time. Please mail the container and badge back to the University of Maine in the postage-paid envelope provided.

Instructions for Keeping Your Activity Record:

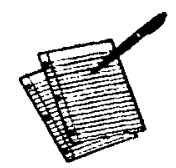

- Please keep a record of your activity during the day that you wear the badge. The next day, we will call you on the phone to talk about your record.

\section{Activity Worksheet}

- Using your "Activity Worksheet," keep track of what you do during each hour of the day. Make sure to record things like watching TV. using the computer, eating lunch, playing outside, or specific activities like riding a bike, jumping rope, walking your dog, and so on.

- When we call you on the phone the next day, we will ask you to tell us your activities and whether you were inside or outside during each activity. 
- For each activity you do, write down when you started and when you finished the activity, but only if you did the activity for 5 minutes or more. Sometimes during activities you may stop and do something different, such as resting or waiting in line. For example, you rode bikes with your friends from 10:30 an until 11:45 am, but during that time you went inside for a glass of lemonade from 11:00 am until 11:10 am. So, on your activity worksheet, write down:

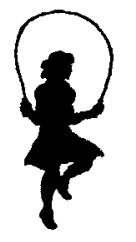

$$
\begin{aligned}
& \text { 10:30 am - 11:00 am rode bikes } \\
& \text { 11:00 am-11:10 am drank lemonade inside } \\
& \text { 11:10 am-11:45 am rode bikes. }
\end{aligned}
$$

- See sample "Activity Worksheet" on back of this page.

The day to wear the badge and keep the activity record kill be THURSOAY, AUEUST 17'H. You will be contacted if this date is changed.

You will be called about your activity record on FRIOAY, AUEUST $18^{\text {TH }}$. A good time to call is AM/PM.

Please do not change your normal behavior for this study.

If you have any questions, please contact Jennifer Cobb or Susan Sullivan.

Phone: 581-3130

E-mail: Jennifer.Cobb@umit.maine.edu 
Sample Activity Worksheet

\begin{tabular}{|l|l|}
\hline Time of Day & \multicolumn{1}{|c|}{ Activity } \\
\hline 8:00 am - 8:15 am & $\begin{array}{l}\text { Got up, got dressed } \\
\text { Ate breakfast }\end{array}$ \\
\hline 8:45 am - 9:20 am & Brushed teeth, made bed, picked up room \\
\hline $\begin{array}{l}\text { 9:20 am - 9:30 am } \\
\text { 9:30 am - 10:30 am }\end{array}$ & $\begin{array}{l}\text { Drove to supermarket with mom } \\
\text { Shopped in supermarket with mom }\end{array}$ \\
\hline 10:30 am - 10:40 am & $\begin{array}{l}\text { Drove from supermarket to home } \\
\text { 10:40 am - 11:00 am } \\
\text { Helped mom put away groceries and ate a } \\
\text { snack }\end{array}$ \\
\hline 11:00 am - 12:15 pm & $\begin{array}{l}\text { Swam in next door neighbor's pool with my } \\
\text { friends } \\
\text { Went home and changed clothes }\end{array}$ \\
\hline $\begin{array}{l}\text { 12:30 pm - 1:15 pm } \\
\text { 1:15 pm - 2:20 pm }\end{array}$ & $\begin{array}{l}\text { Ate lunch outside on our deck } \\
\text { Played computer games }\end{array}$ \\
\hline 2:20 pm - 5:00 pm & Played outside with friends \\
\hline 5:00 pm - 5:15 pm & $\begin{array}{l}\text { Drove to Grandma's house } \\
\text { Ate dinner at Grandma's house }\end{array}$ \\
5:15 pm - 6:30 pm & $\begin{array}{l}\text { Helped clear table and clean up } \\
\text { Drove to Dairy Queen }\end{array}$ \\
\hline 6:30 pm - 7:00 pm \\
7:00 pm - 7:10 pm \\
\hline 7:10 pm - 7:40 pm & $\begin{array}{l}\text { Ate ice cream } \\
\text { Drove home }\end{array}$ \\
\hline 7:40 pm - 7:45 pm & $\begin{array}{l}\text { Got ready for bed } \\
\text { Watched TV }\end{array}$ \\
\hline 8:00 pm - 9:00 pm & Went to bed \\
\hline 9:00 pm & \\
\hline
\end{tabular}




\section{APPENDIX E}

Activity Sheet and Sun-Exposure Questionnaire 
Activity Sheet

\section{The Sunshine Badge Study}

Your Activity Worksheet

\begin{tabular}{|l|l|}
\hline Time of Day & \multicolumn{2}{|c|}{ Activity } \\
\hline 9:00 am - 9:30 am & Ate breakfast \\
\hline & \\
\hline & \\
\hline & \\
\hline & \\
\hline & \\
\hline & \\
\hline
\end{tabular}


Sun-Exposure Questionnaire

Subject:

Date:

24-Hour Recall of Activity and Sun Exposure

Page 1

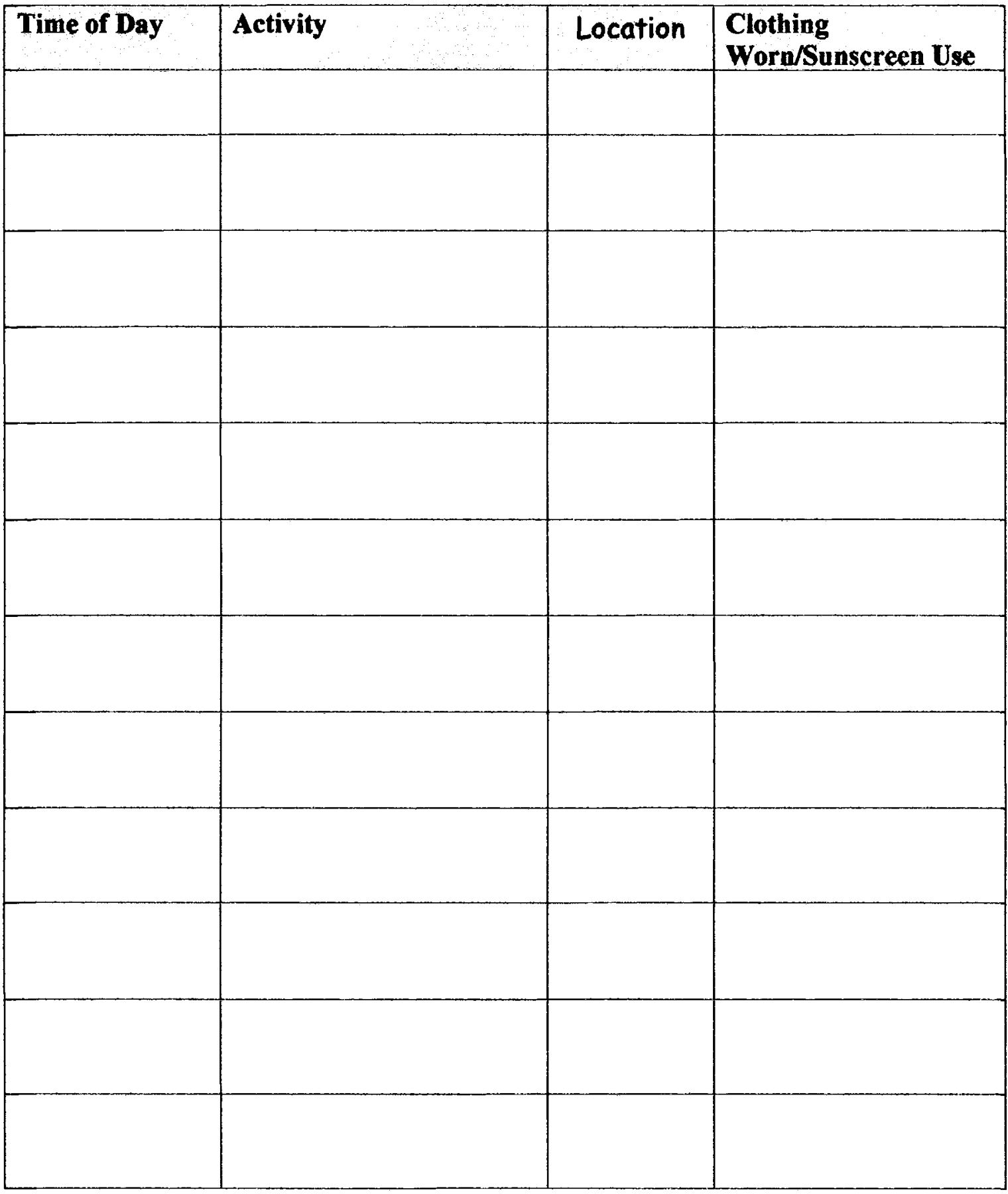


Subject:

Page 2

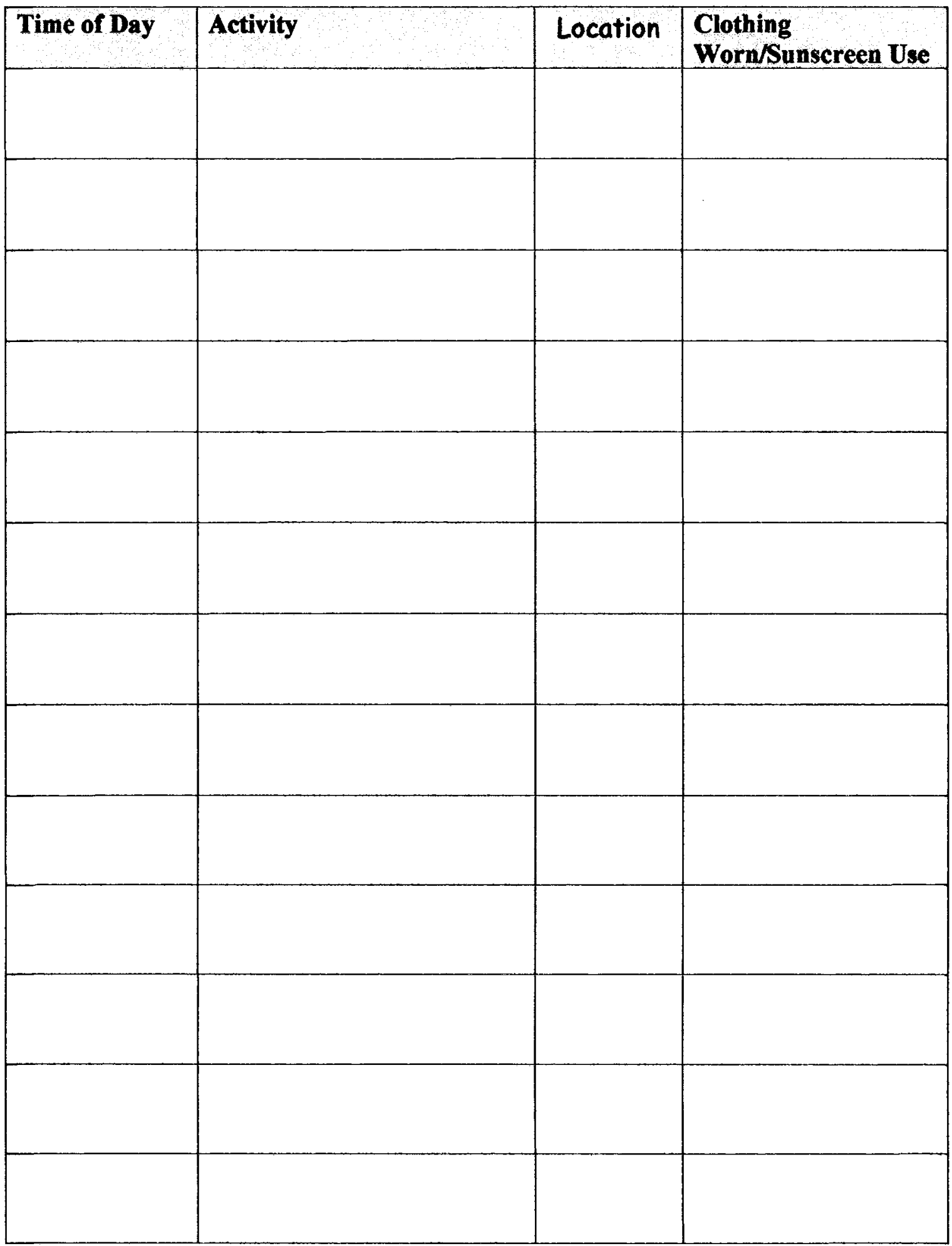


APPENDIX F

Average Hourly UVB

August 17, 2000 


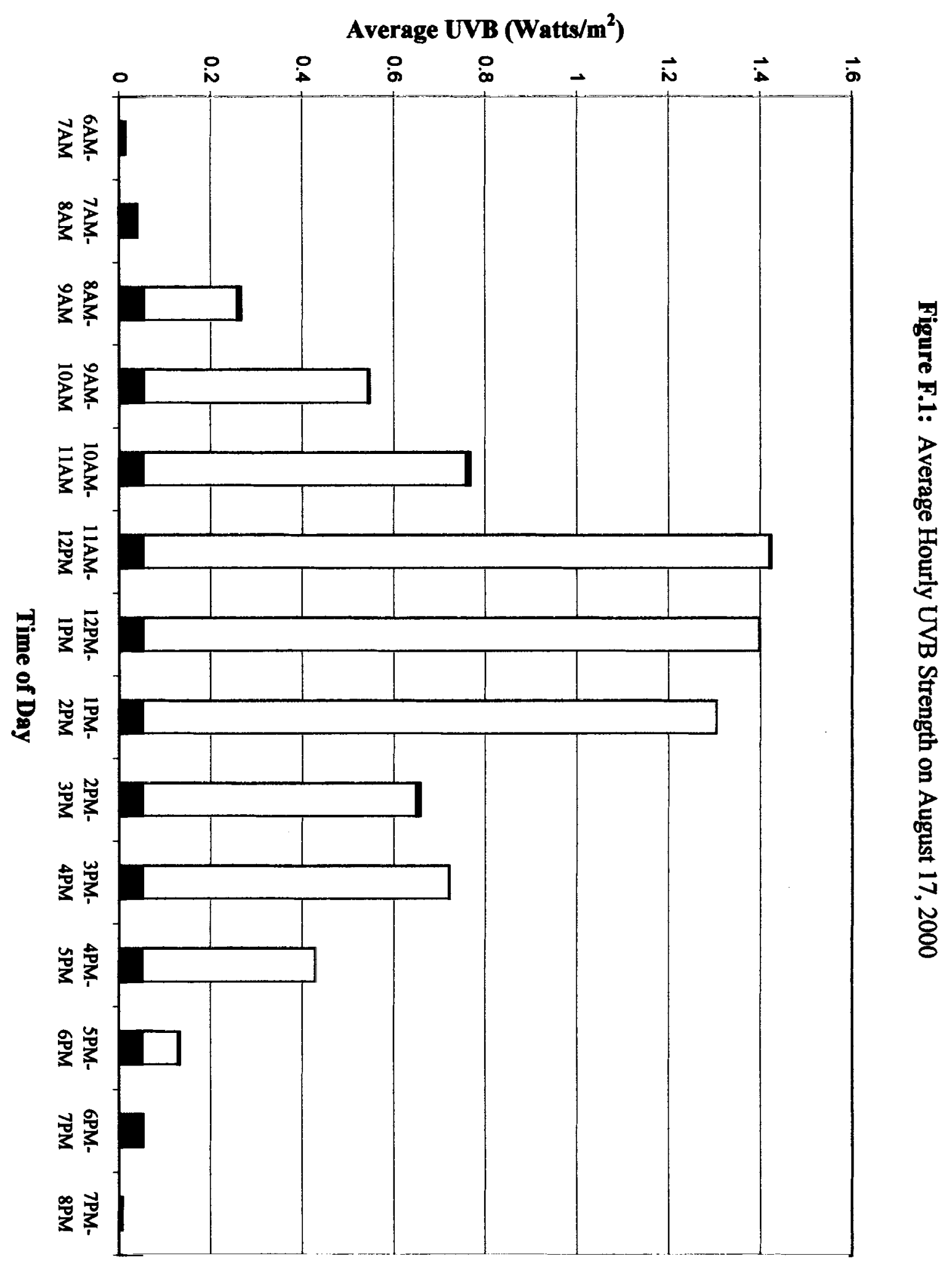


Example of Correcting Subject Minutes Spent Outdoors 
Table G.1

Example of Difference Between Total Minutes Outdoors and Total Minutes Corrected for the Hourly Strength of UVB Rays of the Sun.

ID \#14

\begin{tabular}{|c|c|c|c|}
\hline TME OF DAY & $\begin{array}{c}\text { MINUTES } \\
\text { OUTDOORS } \\
\text { REPORTED BY } \\
\text { SUBJECT }\end{array}$ & $\begin{array}{c}\text { CORRECTION FACTOR } \\
\text { DETERMINED FROM } \\
\text { HOURLY UVB STRENGTH }\end{array}$ & $\begin{array}{c}\text { CORRECTED } \\
\text { MINUTES } \\
\text { OUTDOORS }\end{array}$ \\
\hline 6-7 AM & & 0.01 & 0 \\
\hline 7-8 AM & & 0.03 & 0 \\
\hline 8-9 AM & 15 & 0.19 & 2.85 \\
\hline $9-10 \mathrm{AM}$ & 23 & 0.38 & 8.74 \\
\hline 10-11 AM & 26 & 0.54 & 14.04 \\
\hline $11 \mathrm{AM}-12 \mathrm{PM}$ & & 1 & 0 \\
\hline 12-1PM & & 0.98 & 0 \\
\hline 1-2PM & & 0.92 & 0 \\
\hline 2-3 PM & & 0.46 & 0 \\
\hline 3-4 PM & 8 & 0.51 & 4.08 \\
\hline 4-5 PM & 13 & 0.3 & 3.9 \\
\hline 5-6 PM & 30 & 0.09 & 2.7 \\
\hline 6-7PM & 19 & 0.04 & 0.76 \\
\hline TOTAL & 134 & & 37.07 \\
\hline
\end{tabular}




\section{APPENDIX H}

Original Sun-Exposure Questionnaire 
Sun-Exposure Questionnaire ID \#

For Summer (June-August)

\begin{tabular}{|c|c|c|c|}
\hline $\begin{array}{c}\text { TIME } \\
\text { OF } \\
D A Y\end{array}$ & $\begin{array}{c}\text { USUAL DAILY } \\
\text { OUTDOOR } \\
\text { ACTIVITIES }\end{array}$ & $\begin{array}{c}\text { TOTAL } \\
\text { TIME } \\
\text { SPENT OUTDOORS }\end{array}$ & $\begin{array}{c}\text { CLOTHING } \\
\text { WORN } \\
\text { OUTDOORS }\end{array}$ \\
\hline $\begin{array}{l}7-9 \\
\text { AM }\end{array}$ & & & \\
\hline $\begin{array}{l}9-10 \\
\text { AM }\end{array}$ & & & \\
\hline $\begin{array}{l}10-11 \\
\text { AM }\end{array}$ & & & \\
\hline $\begin{array}{l}11 \\
\text { AM- } \\
2 \text { PM }\end{array}$ & & & \\
\hline $\begin{array}{l}2-3 \\
\text { PM }\end{array}$ & & & \\
\hline $\begin{array}{l}3-4 \\
\text { PM }\end{array}$ & & & \\
\hline $\begin{array}{l}4-5 \\
P M\end{array}$ & & & \\
\hline
\end{tabular}




\section{Sun-Exposure Questionnaire (page 2)}

1. Describe any time during the summer when your outdoor activities were significantly different from your typical day described on the previous page.

\begin{tabular}{|l|l|l|}
\hline Outdoor activity during this time & $\begin{array}{l}\text { Total time } \\
\text { spent } \\
\text { outdoors }\end{array}$ & $\begin{array}{l}\text { Total \# of days } \\
\text { like this during } \\
\text { the summer }\end{array}$ \\
\hline & & \\
\hline & & \\
\hline
\end{tabular}

2. Did you wear sunscreen lotion most of the time (at least $1 / 2$ the time) that you were outdoors? YES NO

If YES, when did you wear sunscreen lotion?

3. To which parts of your body did you usually apply sunscreen lotion? Please check all that apply.

$\square$ Face

$\square$ Arms

Hands

$\square_{\text {Legs }}$

Back and shoulders

All bare skin

4. What number SPF sunscreen lotion do you usually wear? 


\section{BIOGRAPHY OF THE AUTHOR}

Jennifer L. Cobb was born in Millinocket, Maine on January 10, 1968. She was raised at Pierce Pond and North New Portland, Maine and graduated from Carrabec High School in North Anson, Maine in 1986. She attended the University of Maine and graduated with high distinction in 1991 with a Bachelor of Arts degree in Advertising. She returned to the University of Maine in 1997 and graduated summa cum laude in 1999 with a Bachelor of Science degree in Food Science and Human Nutrition. She began her graduate studies at the University of Maine in September 1999. She worked as a research assistant in the Department of Food Science and Human Nutrition from September 1999 to May 2001.

Jennifer is a member of three national honor societies, Kappa Omicron Nu, Phi Tau Sigma and the Golden Key Honor Society. Jennifer's professional memberships include the American Dietetic Association, the Maine Dietetic Association and the SCAN Dietetic Practice Group. She gave an oral presentation entitled "Development of a SunExposure Questionnaire to Assess Potential for Vitamin D Synthesis in the Skin" at an original contributions session at the National American Dietetic Association Convention in October 2000. Jennifer will present her research findings in a poster session at the Biologic Effects of Light Symposium in June 2001. She is a candidate for the Master of Science degree in Food Science and Human Nutrition from The University of Maine in December, 2001. 